\title{
La elocuencia del embajador: don Juan Antonio de Vera y Zúñiga y las Orationi militari de Remigio Nannini
}

\author{
Victoria Pineda \\ Universidad de Extremadura \\ mvpineda@unex.es
}

Recepción: 12/09/2014, Aceptación: 06/10/2014, Publicación: 22/12/2015

\section{Resumen}

El libro de diplomacia El embaxador (1620), escrito en forma de diálogo por don Juan Antonio de Vera y Zúniga, se convirtió tras su publicación en uno de los tratados más influyentes de su género en toda Europa. El contenido y la filiación política del diálogo han sido mencionados con frecuencia en los estudios sobre filosofía política y sobre asuntos de diplomacia, pero poco se ha dicho acerca de las posibles lecturas que habrían influido en la composición de El embajador en lo que atañe al tema de la elocuencia. Este trabajo examina la última parte del diálogo, en la que uno de los interlocutores lee una lista de más de cien oraciones y más de cuarenta autores que el aprendiz de diplomático debería utilizar como modelos de elocuencia. Un análisis detenido de dicha lista revela que la fuente habría sido la antología de discursos Orationi militari, publicada en Venecia en 1557 por Remigio Nannini y más tarde repetidamente reeditada e imitada. El estudio pone de relieve un caso singular del proceso de «apropiación» favorecido por las artes excerpendi de la época.

Palabras clave

Juan Antonio de Vera y Zúñiga; conde de la Roca; El embaxador; Remigio Nannini; Orationi militari; elocuencia militar; diplomacia; artes excerpendi

\footnotetext{
Abstract

Diplomatic eloquence: don Juan Antonio de Vera y Zúniga and Remigio Nannini's Orationi militari

El embaxador (1620) by don Juan Antonio de Vera y Zúniga was a dialogue on diplomacy that became one of the most important treatises of its genre in Europe. Critical studies on political philosophy and diplomacy often mention the contents of Vera's book,
} 
as well as its political affiliation, but very little has been said about the possible readings that might have influenced Vera as far as eloquence is concerned. This article examines the last part of the dialogue, where one of the characters reads a list of more than one hundred speeches and over forty historians that the diplomat-in-training should use as models for eloquence. A close analysis of the list reveals that the source of this section is Orationi militari, an anthology of speeches published in Venice in 1557 by the Dominican friar Remigio Nannini, a collection that would be repeatedly reissued and imitated in later years. This essay highlights a special case of the process of "appropriation" facilitated by some Early Modern artes excerpendi.

\section{Keywords}

Juan Antonio de Vera y Zúńiga; conde de la Roca; El embaxador; Remigio Nannini; Orationi militari; military eloquence; diplomacy; artes excerpendi

Imitaciones tan fieles son, Conde, las que hacéis... El conde de Añover al conde de la Roca, 1632

Cuando don Juan Antonio de Vera publicó en 1620, a los 37 años de su edad, El embajador (Sevilla, Francisco de Lyra), su experiencia en el campo diplomático estaba todavía por desarrollarse plenamente. El texto, sin embargo, estaba llamado a convertirse en uno de los tratados más influyentes en su género en toda Europa, especialmente a través de las traducciones francesa e italiana. Un resumen muy sintético de la obra la describe así:

Descendiente directo del Cortesano de Castiglione, este exitoso libro volvió a servirse de la ilusión del diálogo (Ludovico visita a su amigo Julio en la quinta donde vive retirado) para pasar revista a la formación y cualidades humanas que requiere la carrera diplomática, según la pauta de tantos otros manuales de comportamiento político de los siglos XVI y XVII —las «imágenes» o «retratos» del perfecto príncipe, privado, secretario, consejero, etc. - con los que tiene estrecho parentesco. Muestra de esta literatura ejemplar, que floreció en las cortes europeas del Renacimiento y el Barroco, El Embaxador ha de leerse como una ética de la 
profesión y a la vez como un manual de supervivencia política en una corte extranjera (Colomer 2003: 20).

Su éxito fue inmediato. Ese mismo 1620 Lope de Vega, que le dedica a Vera la comedia Los esclavos libres (incluida en la Parte XIII, publicada en Madrid), confiesa estar aguardando la salida del texto: «Espero los discursos del libro que V.M. llama El Embaxador, materia no emprendida de ingenios en ninguna de las lenguas clásicas, o a lo menos que haya llegado a mis ojos, y digno sujeto del claro conocimiento que V.M. tiene» (p. 564). ${ }^{1} \mathrm{Y}$ otra persona cercana, el duque de Sessa, se dirige en estos términos a Vera a propósito del libro: «Él está escrito con suma erudición, y las materias, tratadas con lo más selecto y aprobado que se puede arbitrar en dificultades tan importantes. Enseña y deleita, y en la dulzura del estilo lucen como piedras preciosas las sentencias; no sé si diga más; pero si todo ha de ser menos, más vale que V.M. agradezca mi deseo, que no me reprehenda mi osadía. Alabo también el cuidado de la impresión, y que tan bien enseña cómo ha de ser; y siempre he pensado que a los libros les sucede lo que a las casas, que el agrado del esterior, luz y jardines obliga a desear vivirlos, como a los libros de la buena impresión a leerlos» (Amezúa 1943: 311). ${ }^{2}$

El contenido y la filiación política del diálogo han sido con frecuencia mencionados en los estudios sobre filosofía política y sobre asuntos de diplomacia (ver solo la bibliografía citada en Colomer 2003), y por ello no voy a detenerme en esos temas. Mi intención, más modesta, es la de añadir una página a los trabajos que exploran las posibles lecturas que habrían influido en la composición de El embajador sobre todo en lo que atañe al tema de la elocuencia. Para ello

1. En realidad, estrictamente hablando, antes de 1620 — con un sistema diplomático perfectamente asentado en todos los países europeos- se habían publicado treinta y seis tratados de diplomacia (Mattingly 1964: 183), algunos de ellos en una lengua tan clásica como el latín; posiblemente Lope haya querido decir autores clásicos, no lenguas clásicas. En todo caso, Vera fue el primer español en firmar la autoría de uno de estos tratados. Para la relación entre Vera y Lope, véase Fernández-Daza Álvarez (1994b). La investigación para este artículo se ha desarrollado en el seno del proyecto de investigación FFI2013-31813 («Proyecto Arenga», de la Universidad de Extremadura) y del Grupo de Investigación HUM023 del catálogo de Grupos de Investigación de la Junta de Extremadura.

2. La carta está fechada a finales de 1620. Año y medio antes Sessa ya sabía de la existencia del tratado y así le escribe, por medio de Lope de Vega, a Vera: «Vm. ha empleado su gran ingenio en materia, a lo que yo imagino, apenas imaginada, y ansí pienso que será recibida, y con las cartas de crédito que ya tengo de su entendimiento y letras, doy por excelentísimo el libro, y las materias de él tratadas con tanto cuidado y propiedad, que enseñen a los que las han de exercitar y admiren a los que las han de leer» (Amezúa 1943: 246). A mediados de 1620 una nueva carta de Sessa nos informa de la censura del libro por parte de Antonio de Herrera (Amezúa 1943: 294-295). Rodríguez Moñino (1935: 28-30) transcribe otros elogios de Lope y Pérez de Montalbán hacia nuestro autor. Y solo dos años después de la publicación de El embajador, Tamayo de Vargas dirá que «es libro que merece ser leído por su importancia, y lo merece por su acierto entre los nuestros como admirado por los extrańos, por ejemplo de lo que pueden en todo los ingenios de España» (citado por Ramírez de Villa-Urrutia 1927: 177). Modernizo los textos castellanos que aparecen en este trabajo, excepto si la modernización supone una variación fonética. 
convendrá decir unas palabras acerca del trasfondo cultural en que se movía don Juan Antonio en los años en que escribió el libro.

De su Extremadura natal Vera había marchado siendo joven a Sevilla para atender a sus estudios, y allí había entrado a formar parte del círculo intelectual de don Gaspar de Guzmán, el futuro conde-duque de Olivares, quien desde 1607 había empezado "a proteger a poetas y artistas", de manera que "podían verse en su compañía algunas de las figuras más destacadas de la vida cultural de la ciudad» (Elliott 1990: 53). Componentes del grupo fueron, entre otros, Francisco Pacheco, Francisco de Rioja, un joven Velázquez, Juan de Fonseca y Figueroa, Juan de Jáuregui y algunos otros «escritores y eruditos a los que posteriormente, durante los años de su privanza» don Gaspar favorecería "con cargos y prebendas» (Montero 2012: 16). Durante las reuniones del selecto grupo don Juan se había destacado en las "conversaciones con tal acopio de datos y citas históricas que más parecía un filósofo e historiador consumado que un joven sin práctica de los negocios políticos y diplomáticos» (López de Balboa en Vera y Figueroa 1947: xvI), y quizá por eso -y por las muestras de dominio del asunto exhibidas en el recién publicado Embajador - fue uno de los elegidos en el patrocinio del ya conde de Olivares. El caso es que a partir de 1621, con Olivares recién elegido como favorito de Felipe IV, Vera fue mandado llamar para ocuparse de la enseñanza de los futuros diplomáticos. Más tarde vendría su nombramiento como Conde de la Roca en 1628 y, entre 1630 y 1644, sus misiones diplomáticas, desarrolladas todas en Italia. ${ }^{3}$

Pero quedémonos en la preparación del texto de El embajador. Cuando lo publica, Vera no había cumplido todavía ningún encargo diplomático internacional, aunque llevaba unos diez años ejerciendo como secretario de don Gómez Suárez de Figueroa, III duque de Feria —él mismo diplomático de Felipe III—, y fue "a partir de esa experiencia y de sus lecturas» como compuso el tratado (Montero 2012: 18). ${ }^{4}$ Una de esas lecturas habría sido el De constantia de Justo Lispio. Como recuerda Elliott (1990: 54), Lipsio fue uno de los autores «que gozaban de mayor favor» en los ambientes sevillanos: fue en Sevilla donde, según testimonio del propio Lipsio, "estaban la mayoría de sus seguidores» y donde se publicó la traducción de la obra en 1616. ${ }^{5}$ Este libro, sigue diciendo Elliott, «in-

3. El mejor documento sobre la actividad de Vera en el período veneciano sigue siendo Cinti (1966).

4. Pero había tenido la oportunidad de formar parte del séquito que acompañaba al duque de Feria en algunas misiones: en 1610, a la muerte del rey Luis de Francia, y con el objetivo de "dar el pésame al nuevo rey y a la reina viuda», Felipe III manda a París al «duque de Feria, que partió de la corte con grande acompańamiento de algunos señores de título, caballeros y criados; uno de ellos fue don Juan Antonio de Vera y Zúñiga» (Salazar de Mendoza 1770: 138). Ver también Fernández-Daza Álvarez (1994a: 62).

5. Libro de la constancia de Justo Lipsio, traducido de latín en castellano por Juan Baptista de Mesa, Sevilla, Matías Clavijo, 1616. Aunque, como vemos, la traducción aparece atribuida a Juan Bautista de Mesa, es probable que su autor fuera Tomás Tamayo de Vargas (Cantarino 2004: 460). 
fluyó en gran medida tanto en la forma como en el contenido de El embajador, vademécum para diplomáticos ... Los diálogos de Vera están profundamente influidos por Tácito y Justo Lipsio» (1990: 54-55). Temas como el comportamiento público y privado de los individuos, la oposición entre la vida cortesana y la vida del campo o la licitud de la disimulación se hallarían entre los que Vera toma de sus modelos.

La dependencia de Vera con respecto a Lipsio fue ya advertida por un contemporáneo suyo, Antonio Hurtado de Mendoza, dramaturgo y secretario del Rey, y muy cercano a Olivares. Cuando Vera mostró sus intenciones de escribir la biografía del Conde-Duque, Mendoza lo acusó de haber impreso «un libro que llamó El embajador, copiado a trozos de la Constancia de Justo Lipsio» (citado en Davies 1965: 161-162). La cita es importante porque nos da la idea de cómo componía Vera y de cuán poco se cuidaba de disimular sus fuentes. De hecho, el estudio llevado a cabo por Davies sobre la relación de los dos escritos, el de Lipsio y el de Vera, lleva a la conclusión de que "The Embaxador is ... a farrago, in which Juan de Vera drew on his very considerable knowledge of classical and contemporary history. The merit of the text ... lies in its use of multifarious material in such a way as to provide the diplomat with a host of practical examples» (1965: 162). ${ }^{6}$ Así, el texto de El embajador se nos aparece en ciertos lugares casi como una labor de taracea, un conjunto de piezas sacadas de aquí y de allá, elaboradas, muchas veces amplificadas, y ensambladas (gracias, entre otras cosas, a las posibilidades que ofrece el género dialogístico) en un conjunto no siempre orgánico.

Los textos que aduce Davies para mostrar el paralelo entre Vera y Lipsio (no solo el De constantia, sino también los Politicorum libri sex) no dejan lugar a dudas acerca del parentesco y revelan además una coincidencia de términos y frases enteras que solo pueden sugerir el hecho, no irrelevante, de que Vera usó las traducciones castellanas de ambos libros. Davies (1965: 162) también señala «a long translation» de un pasaje de Il messaggero de Torquato Tasso, autor muy del gusto de don Juan Antonio, quien volverá a utilizarlo en el insólito «poema heroico» El Fernando o Sevilla restaurada (1632), escrito, según reza el título, "con los versos de la Gerusalemme liberata», en el que parafrasea el poema de Tasso haciendo protagonista del texto al rey Fernando III. Vera no oculta - $\mathrm{O}$ no siempre- sus fuentes y, cuando puede, salpica su texto de nombres, ya sea en forma de cita o de exemplum, en una práctica compartida con la inmensa mayoría de los escritores de su generación. El embajador nos ofrece efectivamente un repertorio de citas y nombres que, según Mattingly (1964: 183), indicaría que «he had read widely ... and had most of the more important writers on diplomacy either in memory of at hand». Mattingly se está refiriendo, como vemos, al conocimiento de Vera de sus precedentes en el campo de la tratadística diplomá-

6. Para un desarrollo ulterior de esta idea, consúltese el trabajo de Delage (2007). 
tica, pero podría decirse que ese tipo de erudición (exhibida con «aristocrática despreocupación» — «aristocratic nonchalance»—) permea a la obra entera.

El embajador trata de los diversos aspectos relacionados con el arte de la diplomacia. Son temas que en líneas generales se corresponden con los de otras obras de su género (la estirpe del candidato a diplomático, su aspecto físico, su preparación, sus aptitudes e inclinaciones, su comportamiento, sus deberes, los tipos de embajada, etc.). Al tratar de la preparación intelectual del futuro embajador los tratados suelen mencionar el dominio de la elocuencia como cualidad indispensable. Como ha documentado Mattingly (1964: 186), todos los autores insistían en que «the perfect ambassador had to be deeply read in literature and eloquent in the Latin tongue, for to be an orator was the ambassador's office». La elocuencia ocupa, en efecto, la atención de Vera en dos puntos del libro: el primer y el último «discurso».

Hacia el final del primero de los cuatro «discursos» de que se compone el libro, Ludovico, uno de los dos interlocutores, declara que las armas de la persuasión son la razón y el ejemplo, en palabras que remiten en su origen a las pruebas artificiales de las que habla Aristóteles en la Retórica. El embajador, asegura, se esforzará en usar "todo el arte de la persuasión, y porque la persuasión se hace con fuerza de razones, de ejemplos, de afetuosos movimientos y autoridad de costumbres, debe el legado en las razones y ejemplos elegir no solo los más fuertes, sino los más gratos, de que saque alguna utilidad aquel por quien se hacen» (f. 67).7 Un poco más adelante sentencia: «No puede uno ser buen embajador sin ser buen orador, porque todo el oficio se reduce a persuadir o a disuadir, y esto, sin copia de elegancia retórica y caudal natural, no se pondrá bien en práctica, y, como dicen muchos, de aquí tiene origen que los latinos llamen comúnmente 'orador' al embajador» (f. 67v). Y, siguiendo sus propios consejos, las páginas que siguen se llenan con ejemplos que confirman la necesidad de la elocuencia en el embajador, para culminar con una descripción desmenuzada del arte oratoria: «¿Quién inora que la locución, frasis, términos y interrogaciones, iras, esclamaciones, sumisiones y otras mil figuras son las partes de que se forma la elocuencia?, ¿ni ser la elocuencia la alma de la persuasión, y la persuasión, el todo de la embajada?» (ff. 69-69v). El resto del discurso primero está salpicado de ejemplos de arengas y oraciones pronunciadas por diversos personajes históricos o ficticios. Así, por ejemplo, en el f. 49 encontramos una oración de Herodes a los judíos; más adelante (ff. 62v-63) algunas de los embajadores Argante y Aleto, de la Gerusalemme liberata de Tasso (obra que Vera se afanó en traducir para más tarde reconvertirla en el poema El Fernando citado antes), luego,

7. Téngase en cuenta para la identificación de la foliación que esta no es correlativa de principio a fin, sino que los tratados tienen numeración independiente: los discursos primero y segundo forman una unidad (respectivamente ff. 1-84 y 85-152, cuadernillos A-T), y el tercero y el cuarto, por su parte, otra (ff. 1-71 y 72-131, cuadernillos Aa-Rr), con la «Tabla alfabética» final sin foliar ni paginar. 
una embajada de Ilioneo, el personaje virgiliano (f. 70), más de la Gerusalemme (ff. 70v, 71), una oración del embajador del rey de Sicilia Germán Candelas sacada de Zurita (f. 143v) y fragmentos de otras varias arengas y discursos. Vera hace hincapié en el efecto práctico de los ejemplos que propone y garantiza que la asimilación de los textos «no podría dejar de hacerle elegante y profundo orador» (f. 77) a cualquier embajador que los «tomase de memoria» (f. 76). ${ }^{8}$

La segunda ocasión en que los interlocutores se refieren a esta materia llega al final del último discurso y, por lo tanto, al final de la obra. En el «Sumario» del mismo que va al frente ya leemos el adelanto: «Lee Ludovico un discurso que tiene hecho, acomodando las más ecelentes oraciones que hay esparcidas en los más famosos historiadores a las diferentes ocasiones que a un embajador se le suelen ofrecer, en que hacer ostentación, de palabra o por escrito, de su caudal. Con que se da fin al último discurso de este libro» (f. 72v). El anuncio promete lo que parece ser el complemento práctico perfecto para la teoría sobre la elocuencia del embajador expuesta en la primera parte del libro. Y, efectivamente, a la altura del folio $122 \mathrm{v}$, Ludovico recuerda:

Lo que falta ahora es leer los discursos de los historiadores aplicados al uso de los embajadores, que espero que ha de ser escelente remate de tarde ... Este papel tenía en bosquejo días ha, aplicando en él a los negocios y ocasiones que se suelen ofrecer a los embajadores, los concetos y discursos de las oraciones de más cuenta que hay esparcidas en los historiadores antiguos y modernos, procurando con tanto cuidado adjudicar bien concetos a necesidades que, si no en el todo, en parte valga el trabajo hecho de los escritores a la persuasión que hubieren de hacer los embajadores, y por lo menos valdrá lo que la primera reja que se da a la tierra nueva.

Y, a petición de Julio, Ludovico comienza la lectura de páginas y páginas (más de dieciséis) en que se contienen largas listas de referencias a oraciones pronunciadas por embajadores de todas las épocas y recogidas por distintos historiadores. Las listas están organizadas según el tipo particular de embajada, y la identificación de las oraciones se hace por el personaje que pronunció el discurso, el receptor y la ocasión del mismo, así como por el autor que transcribió el texto y, a veces, por indicaciones más concretas, como una alusión al título de la obra o el número del libro o la sección donde se registra la oración.

Vera cita más de cien oraciones y más de treinta autores en lo que parece un formidable ejercicio de erudición. Por suerte para él, sin embargo, el trabajo estaba ya hecho. Cuando compuso El embajador, el autor tenía a su disposición

8. Con el mismo propósito se transcriben en el discurso segundo un buen número de cartas de embajadores. Tanto los discursos como las cartas y otras citas, así como también los resúmenes del contenido y las enseñanzas que se pueden sacar de los textos (que se recogen en las apostillas marginales) van resaltadas tipográficamente, al estar impresas en cursiva y destacar, por ello, del resto del texto. 
cualquiera de las varias antologías de discursos extraídos de obras históricas que circulaban en Europa desde hacía décadas. Eran colecciones que cubrían diversas áreas y enfoques: oraciones antiguas y modernas, en lenguas clásicas o en lenguas vulgares, de un solo autor o de muchos, provenientes de obras históricas o ficticias, con orientación pedagógica o sin ella, etc. ${ }^{9}$ La primera gran antología de la época moderna había sido impresa en 1557 en el taller de Giolito de' Ferrari en Venecia, y en ella el fraile dominico Remigio Nannini había recogido una voluminosa colección de Orationi militari raccolte ... da tutti gli historici Greci e Latini, antichi e moderni con gli argomenti che dichiararono l'occasione per le quali elle furono fatte, dove sommariamente si toccano l'historie. Y esta es precisamente la fuente de El embajador. De los 31 autores que cita Vera, 29 aparecen en Nannini, y de la lista de este solo 5 no han sido recogidos por aquel (ver Apéndice). Se trata, pues, de una coincidencia casi absoluta. ${ }^{10}$ Es más, Vera no incluye ninguna oración que no esté en Nannini (hablo, naturalmente, de los autores que citan ambos), y la identificación de los discursos de hace de manera muy similar, aunque resumida, en $E l$ embajador. Podemos afinar un poco más y concretar que de las tres ediciones de las Orationi de Nannini $(1557,1560,1585)$, Vera usó la segunda o la tercera, porque uno de los autores que cita es Plutarco y este no aparece en la primera edición.

En esas dos ediciones el lector Vera habría dispuesto, además, de varios índices y tablas que le habrían hecho más fácil la tarea de localizar una determinada oración, autor o tema. Se presenta en primer lugar la «Tavola delle materie che si contengono nella presente opera» (f. *iiii v, cito por la segunda edición, Venecia, Giolito, 1570), donde las oraciones se clasifican en rúbricas como las siguientes: «Orationi per trattar di leghe», «Per dissuadere una guerra», «Per persuadere una guerra», «Per trattar di pace», etc. A continuación, la «Tavola di tutte l'orationi appartenenti a' capitani, consiglieri et ambasciadori» (f. [ $\left.{ }^{*} \mathrm{v}\right]$ ) se divide según la tripartición anunciada en el título, de manera que la primera sección, que agrupa a las oraciones pertenecientes a los embajadores, le habrá resultado especialmente útil a Vera, que habría seguido el orden indicado en las tablas y no el orden cronológico de los autores incluidos en la antología. Otra tabla, que viene a continuación de esta, es un extenso índice «di tutte le sentenze notabili che si contengono nel presente libro» (f. $\left.{ }^{* *} \mathrm{v}\right)$, en

9. Véanse los trabajos reunidos en Iglesias-Zoido y Pineda (en prensa).

10. La antología de Nannini había sido luego traducida al francés y ampliada por François de Belleforest en 1572 (Harengues militaires et concions de princes, capitaines, embassadeurs, et autres manians tant la guerre que les affaires d'Estat, París, Nicolas Chesneau), pero podemos estar seguros de que el texto que sirvió de modelo a Vera fue el de Nannini porque en su lista no incorpora ninguno de los más de veinte autores añadidos por Belleforest, y porque además cita uno, el Origen de los bárbaros, que no está en la versión francesa. Además de estas dos antologías «enciclopédicas», se publicaron en el siglo xvı otras dos colecciones importantes: la de Henri Estienne, Conciones sive orationes ex Graecis Latinisque historicis (1570), y la de Melchior Junius, Orationum ex historicis tam veteribus quam recentioribus (1598), pero un cotejo preliminar muestra que ninguna de ellas es la fuente de Vera. Pueden encontrase estudios sobre las cuatro colecciones en Iglesias-Zoido y Pineda (en prensa). 
donde Vera también podría haber encontrado con cierta facilidad los temas que le interesaban especialmente. Y un cuarto índice da la relación de autores incluidos en la antología. Hay que decir, sin embargo, que don Juan Antonio ni mucho menos se limitó a seguir mecánicamente los índices ni a trasladar las listas de las tablas al pie de la letra. Una prueba es que la tabla de discursos solo de embajadores (es decir, sin contar los de consejeros y capitanes) de Nannini contiene 66 entradas, y las oraciones citadas por Vera llegan a 118. Por otra parte, la tabla ordena el material cronológicamente, que es la manera en que las arengas van en el libro, empezando por Tucídides y terminando por los autores contemporáneos a Nannini, mientras que Vera sigue, como hemos dicho, un orden temático, pero incluso dentro de cada categoría, las oraciones no siguen un orden cronológico preciso (si acaso, en algunas ocasiones, un curioso orden cronológico inverso).

En el Apéndice podrá comprobarse la correspondencia de todas las oraciones, pero puede ser interesante dar aquí un ejemplo que ilustre el procedimiento que sigue Vera. Tomemos la primera categoría de discursos, que son aquellos que se ajustan a las siguientes "ocasiones»:

Para pedir un socorro, hacer una liga y confederación, demostrando un embajador que el peligro de su dueño es común al rogado y que aunque no sea por obligación y amor, por razón de estado y conveniencia propia, se debe acudir al caído cuando de su ruina crece tanto el ajeno poder que pueda dañar a otros. Iten, para solicitar a un príncipe que haga guerra a otro porque la diversión enflaquezca aquel poder que comienza a ser sospechoso a los demás, y para disponer muchas ligas entre muchos y desbaratar las hechas con otros, con documentos, reglas y avisos maravillosos, son elegantes discursos y oraciones... (f. 123).

Notamos primeramente que algunas de las expresiones que usa pueden recordar a las de la tabla de Nannini («oratoni per trattar di leghe», "per persuadere una guerra»), aunque, como se apuntó antes, las descripciones de Vera son mucho más detalladas y, si se han inspirado en Nannini, se trata de un eco lejano. En la coincidencia de las oraciones, en cambio, está claro el parentesco, como se podrá comprobar en el Apéndice. El mismo sistema se sigue en cada una de las 25 categorías que componen la clasificación de Vera.

Tal es la fidelidad a Nannini que lo que acaba llamando la atención son las discrepancias con respecto a su fuente. Como quedó dicho, son cinco los nombres de la antología de Nannini que El embajador no incluye: Jenofonte, César, Amiano Marcelino, Galeazzo Cappella y el cardenal Bembo. Es difícil encontrar en estas ausencias algún significado retórico, intelectual o político. Quizá Vera no recurrió a estos autores simplemente porque le fue difícil cuadrar sus oraciones dentro de las categorías que había establecido (aunque tampoco sería descabellado pensar que esas categorías fueron confeccionadas, al menos en parte, a la vista del caudal de oraciones). En todo caso, se trata de un porcentaje poco significativo.

Al otro lado, el material que don Juan Antonio aporta de su cosecha a la lista, aunque bien magro, pues se trata únicamente de dos autores, puede tener más re- 
levancia, ya que es bastante probable que se trate de autores que Vera sí había leído de verdad. Los dos autores son Torquato Tasso y Gerolamo de Franchi Conestaggio. Tasso, ya lo hemos dicho, era poeta estimadísimo de Vera, y, como sabemos, la traducción de la Gerusalemme liberata ocupaba los esfuerzos de nuestro autor. La oración que trae para ilustrar la categoría de «ostentar gentileza y generosidad, ofreciendo paz, tregua o liga, cuando interiores necesidades obligan a ello, y no pura virtud» (f. 129v) es la de Aleto, embajador de Egipto, a Gofredo, la misma que páginas atrás había empleado como muestra de la traducción del poema de Tasso y como ilustración del valor de la elocuencia (f. 71 del discurso primero).

La otra obra incorporada por Vera es la Historia delle guerre della Germania inferiore de Ieronimo Conestaggio, publicada en 1614 (Venecia, Antonio Pinelli), que trata, como anuncia la carta al lector, "delle moderne istorie de' Paesi Bassi, tutta piena delle più atroci, più lagrimevoli e più difficili guerre di quanti se ne sieno mai sentite» (f. $\uparrow 3$ ). Puede sorprender que Vera y Zúńiga, destinado a formar parte del cuerpo diplomático encargado de representar al monarca espańol, se refiera a Conestaggio, sabiendo que su obra censuraba abiertamente el comportamiento de Felipe II en Flandes, motivo por el cual había sido recibida con hostilidad en España, como testifica la «cantidad de obras que se escribieron en su contra» (López López 2012: 581) o el informe que preparó Pedro de Valencia desaconsejando su publicación en España. ${ }^{11}$ Pero también es cierto que la Historia de Conestaggio exhibía un artificio «elocuente y retórico», como habrían de reconocer por aquellos años el propio Pedro de Valencia o Lope de Vega. ${ }^{12}$ Vera cita dos oraciones que Conestaggio inserta en la misma escena, la de la consulta del Rey con los hombres de su consejo sobre los asuntos de Flandes: «Cinque erano i consiglieri, Fernando Alvarez di Toledo, Duca d'Alva, Maggiordomo maggior del Rè, l'Inquisitor maggiore, Diego di Spinosa, Ruys Gomes di Silva, Gomez di Figueroa, Duca di Feria, e il padre Bernardo di Fresneda, confessor del Rè. I due primi consigliavano la guerra, gli altri tre volevano la pace» (80). Se trata de uno de los muchos casos en que los historiadores representan las oraciones de dos partes enfrentadas, según una costumbre que se remonta a la historiografía clásica. En este caso las dos posturas están encarnadas por el duque el Alba, que es el pri-

11. Puede leerse el texto del informe en la edición de López López (2012).

12. "Me parecen muy bien [las Guerras de Flandes] en cuanto al ingenio, elocuencia y artificio del autor» (informe de Pedro de Valencia sobre la obra de Conestaggio, López López 2012: 585). En La Circe (1624) Lope incluye la «Epístola a Fray Plácido de Tosantos», donde se leen estos versos: «Mas a quién no dará mortal disgusto / un estranjero historiador, hablando / de Felipe Segundo, siempre augusto, / que, las guerras de Flandes dilatando / elocuente y retórico, mintiendo, / con artificio vil le está culpando. / Y un fiero calvinista engrandeciendo, / que le pagó muy bien lo que escribía ... Pues en el siglo desta edad segundo / ¿quién no creerá que el Franqui Conestagio / dijo verdad? Luego en verdad me fundo" (ff. 160v-161). El libro de Conestaggio debía de ser objeto de polémica en los años veinte, como muestra, entre otros documentos, la obra de Juan Pablo Mártir Rizo de la Historia de las guerras de Flandes contra la de Geronimo de Franqui Conestaggio (1627), traducción del original francés de Pierre Matthieu. 
mero en tomar la palabra, y por Fresneda, que habla a continuación. El discurso del duque será empleado por Vera para ilustrar dos de sus categorías de misiones aconsejadas para los embajadores: en primer lugar, para «facilitar una empresa ardua, sea militar o civil, y contrastar la opinión que la disuade, encargara yo a todo embajador que la tuviese a su cuidado» (f. 127v); y, en segundo, para «malquistar un vulgo con su príncipe, república o gobierno» (f. 130). Por su parte, el discurso del confesor sirve como ilustración de las ocasiones en que haya necesidad de «disuadir un embajador al príncipe asistido de la empresa que trata contra el propio o contra otro, diminuyéndole las causas en que la funda y ponderándole la resistencia que hallarán sus disinios» (f. 124v). No es extraño que Vera se hubiese fijado precisamente en este pasaje, siendo uno de sus protagonistas el duque de Feria, el abuelo del noble a quien servía como secretario.

En conclusión, podemos decir que estas páginas del libro de Vera y Zúńiga (que en el tratado se integran casi con dificultad, como una especie de apéndice final) son importantes para la historia de la retórica y de la historiografía por varios motivos. En primer lugar, y aunque no podamos detenernos en un análisis más pormenorizado del asunto, porque la manera de proceder del autor apunta a una manera de leer la historia en que la extracción y selección de textos se revela fundamental. Una escena del discurso primero es, en este sentido, muy expresiva: al tratar de la elocuencia necesaria en el embajador, los personajes van proponiendo, como vimos, ejemplos de discursos, y en un determinado momento, Julio, ponderando una oración de la Gerusalemme de Tasso, exclama: «No es posible, Ludovico, que cosa superior haya ni de todo lo más puro del arte de la Retórica se puede sacar mayores precetos que los que allí se leen ni donde pueda amaestrarse mejor un embajador; y porque veáis y acreditéis lo que os digo, en el cuaderno que está sobre este escritorio presumo que, entre otros trabajos de un amigo nuestro, está traducido este pedazo de oración» (ff. 70v-71). Ese «cuaderno» con traducciones y «otros trabajos» nos habla de una forma de lectura en que el anotador se apropia del texto leído para conformar el edificio del conocimiento en unos nuevos moldes. No son pocos los testimonios de educadores y filósofos renacentistas que aconsejan la manera en que esta labor de "apropiación» ha de llevarse a cabo. Juan Luis Vives, por citar un caso temprano de entre otros muchos, aconseja que los alumnos dispongan de dos libretas, una grande y una pequeña, la primera reservada para anotar las explicaciones del maestro, y la segunda, para aquellas palabras, expresiones, nombres, dichos, sentencias, narraciones históricas, etc., que les conviene recordar. A la vez, cada alumno ideará un sistema de señales o marcas que le servirán de referencia cruzada en su lectura de los autores (Vives 1536: 296-297). ${ }^{13}$ El hecho

13. No pretendo sugerir un parentesco directo entre Vera y Vives, sino tan solo subrayar la existencia de una tradición metodológica que prevé una forma de lectura apoyada en el extracto de autoridades. Egido (1997: 40-45) recuerda otros autores que trataron el asunto en manuales retóricos o pedagó- 
de que Ludovico esté confeccionando una antología a partir de otra antología en modo alguno merma el valor de la operación, sino que más bien muestra hasta qué punto son flexibles los límites del excerpere.

En segundo lugar, esta última sección del libro de Vera y Zúñiga es importante porque nos permite estudiar un caso vivo de recepción, de lectura y re-apropiación de una colección en la que el componente retórico está presente de manera sustancial. El tema de la elocuencia, al insertarse en una obra de alto contenido político, cobra unos contornos que nos transportan a la Antigüedad clásica, cuando el ejercicio de la oratoria tenía un alto valor político y cívico. Vera recupera ese espíritu y ennoblece la figura del embajador al encarnarla en los grandes oradores de la historia.

Finalmente, son páginas significativas porque revelan que la labor de agrupación de las oraciones según su contenido conduce a una organización particular del edificio de la teoría diplomática. Vera ha rehecho la antología de Nannini completándola, vivificándola, dándole un nuevo sentido. Este valor epistemológico queda plasmado gráficamente cuando leemos la lista de «ocasiones» para las que las oraciones propuestas pueden ser útiles: esa lista condensa de alguna manera todos los oficios del embajador y nos los presenta en el orden que más se adapta a las intenciones del tratadista. Como reconoce Nakládalová (2012: 767), el excerpere "proporciona una garantía eficaz contra el saber desordenado y caótico; presupone una reducción esencial del conocimiento a una cantidad textual abarcable».

Puede ser interesante comprobar, para terminar, qué hicieron los traductores con estas páginas finales del tratado. Como dijimos, El embajador fue traducido primero al francés por Nicolas Lancelot y publicado en París con el título Le parfait ambassadeur en 1642. Esta edición no solo traduce la lista de las oraciones recomendadas, sino que le da un realce especial al aislarla del resto del texto y darle un título propio: «Indice des plus belles harangues dispersees en tous les historiens, tans anciens que modernes, apropriees aux plus importantes matieres de l'ambassade» (p. 585). El «índice», que se prolonga hasta la página 602, alterna tipográficamente la letra redonda para el enunciado de las ocasiones de embajada y la cursiva para la referencia a las oraciones, simplificando

gicos. Bouza (1999: 84) cita casos concretos de cartapacios españoles conservados. Moss (1996: 88) traduce el siguiente fragmento del Opusculum de discipulorum officiis: quod enchiridion scholasticorum inscribitur (Colonia, 1505) de Johannes Murmellius: «At the suggestion of his teacher, the diligent student should carefully correct his textbooks, pick out phrases and pithy remarks [sententiae] by inserting indicators, put a mark against the most memorable passages [loci], or better still, excerpt them, and write what he has extracted in a little book designed for the purpose». Las artes excerpendi están recibiendo una cierta atención crítica en los últimos tiempos: véanse, por ejemplo, los trabajos de Cevolini (2006), con atención especial a las técnicas de memoria; Nakládalová (2012), para una revisión del corpus y una propuesta del excerpere en tanto operación de sistematización de los saberes; o Yeo (2014), con el estudio de varios casos particulares. 
así la tarea de la lectura, que en la edición sevillana es más complicada, al no existir distinción tipográfica alguna. En 1649 apareció la traducción italiana de Muzio Ziccata, Idea del perfetto ambasciadore, impresa en Venecia en el taller de Wiffeldick. Esta edición, en cambio, ha eliminado por completo la lista de oraciones, ¿quizá por considerarla superflua?, ¿por pensarla excéntrica con respecto al contenido principal?, :porque el traductor, que trabajaba en Venecia, donde se imprimen tanto la traducción de El embajador como el original de Nannini, vio el parentesco y le pareció, como al secretario Antonio Hurtado de Mendoza, que los préstamos que Vera tomaba de otros autores eran demasiado evidentes? Difícil saberlo.

Pero si el trabajo de don Juan Antonio de Vera y Zúñiga quizá no alcance los requisitos para ser considerado - al menos para los párrafos que hemos examinado aquí- como «auténtica» erudición, sí constituye un sugestivo ejemplo de una forma de entender la lectura de la historia y de hacer teoría política en la Edad Moderna. 


\section{Apéndice}

Se registran en este apéndice las categorías en que Vera agrupa las oraciones que extrae de la antología de Nannini. A continuación del enunciado de cada categoría aparece la tabla de correspondencia para esa categoría, con la transcripción de las oraciones citadas por Vera en la columna de la izquierda; en la columna de la derecha doy la correspondencia con la oración contenida en Nannini, y el título que esta lleva en la antología, con indicación de la página de la segunda edición (nótese que las páginas de Nannini no obedecen a un orden ascendente pues, como se ha dicho, Vera no se habría guiado por el orden «natural» del libro, sino más bien por los tipos de discursos indicados en los índices de Nannini). ${ }^{14}$ Con una X señalo las referencias incorporadas por Vera que no están en Nannini.

1 ) [f. 123] Para pedir un socorro, hacer una liga y confederación, demostrando un embajador que el peligro de su dueño es común al rogado y que aunque no sea por obligación y amor, por razón de estado y conveniencia propia, se debe acudir al caído cuando de su ruina crece tanto el ajeno poder que pueda dañar a otros. Iten, para solicitar a un príncipe que haga guerra a otro porque la diversión enflaquezca aquel poder que comienza a ser sospechoso a los demás, y para disponer muchas ligas entre muchos y desbaratar las hechas con otros, con documentos, reglas y avisos maravillosos, son elegantes discursos y oraciones:

Sabelico, libro 9, década 2, en la oración que el embajador florentín hace al senado [f. 123v] de Venecia;
Orationi militari di Marco Antonio Sabellico tratte dalle tre deche della historie di Venetia ... [p. 794] Orationi del nono libro della seconda deca. Oratione di Lorenzo Ridolfi, gentilhuomo Fiorentino, Ambasciadore de' Fiorentini, fatta nel Senato Venetiano, per ottenere aiuto dalla Republica di Venetia nella guerra che faceva loro Filippo Visconte, Duca di Milano.

14. Corrijo, sin advertirlo, las escasas malas lecturas del texto de Vera, que se producen casi todas en nombres propios, probablemente por ignorancia del cajista («Centurio» por Centorio, «Alicarnaser» o «Licarnaseo» por Halicarnaseo, «Tricidades» por Tucídides, «Salucio» por Salustio, «Corço» por Corio, «Cumene» por Eumenes, «Cartugolo» por Cortugolo, «Gilmier» por Gilimer, «Livio» por Vibio). Cuando existen discrepancias de Vera con respecto a su fuente, las señalo en nota. 


\begin{tabular}{|c|c|}
\hline $\begin{array}{l}\text { y la del libro } 5 \text { de la Historia de Flo- } \\
\text { rencia, hecha por Reinaldo Albeci al } \\
\text { duque de Milán; }\end{array}$ & $\begin{array}{l}\text { Orationi militari tratte da gli otto libri } \\
\text { delle Historie di Fiorenza }{ }^{15} \ldots \text { [p. } 868 \text { ] } \\
\text { Orationi del quinto libro. Oratione di } \\
\text { Messer Rinaldo de gli Albizi, fuorusci- } \\
\text { to di Fiorenza, al Duca di Milano per } \\
\text { moverlo a far guerra a' Fiorentini. }\end{array}$ \\
\hline $\begin{array}{l}\text { y la del embajador de la ciudad de } \\
\text { Bonifacio hecha a la república de Gé- } \\
\text { nova, que refiere Agustino Justiniano } \\
\text { en el libro } 5 \text { de su Historia de Génova; }\end{array}$ & $\begin{array}{l}\text { Agostino Giustiniano ... I sei libri de' } \\
\text { suoi annali delle cose di Genova ... } \\
\text { del quinto libro ... [p. 880] Ragio- } \\
\text { namento del ambasciadore della città } \\
\text { di Bonifacio a' Genovesi, la quale era } \\
\text { assediata dal Re Alfonso, chiedendo } \\
\text { soccorso per non vernire nelle mani } \\
\text { del Re. }\end{array}$ \\
\hline $\begin{array}{l}\text { y en la oración de M. Farinata, emba- } \\
\text { jador de Florencia, al rey Manfredo, } \\
\text { que refiere Leonardo Aretino en el li- } \\
\text { bro } 2 \text { de la Historia de Florencia; }\end{array}$ & $\begin{array}{l}\text { [p. 728] Orationi di Lionardo Areti- } \\
\text { no, tratte da' dodici libri dell'Histo- } \\
\text { rie di Fiorenza. Del secondo libro. } \\
\text { Oratione di M. Farinata de gli Uberti } \\
\text { four uscito di Fiorenza e capo della } \\
\text { parte Ghibellina al Re Manfredi, do- } \\
\text { mandando aiuto contra gli avversarii } \\
\text { loro, che gli perseguitavano e cercava- } \\
\text { no di fargli cacciar di Siena, dove ci } \\
\text { s'erano fuggiti. }\end{array}$ \\
\hline $\begin{array}{l}\text { y la oración del embajador de Milán } \\
\text { en Francia solicitando la guerra con- } \\
\text { tra el rey de Nápoles que se lee en } \\
\text { Paulo Jovio, libro } 1 \text { de su Historia; }\end{array}$ & $\begin{array}{l}\text { [p. 908] Orationi militari di Monsi- } \\
\text { gnor Paulo Giovio tratte dalla prima } \\
\text { parte dell'Historie de' suoi tempi. } \\
\text { Del primo libro. Oratione di Carlo } \\
\text { da Balbiano, ambasciador di Lodo- } \\
\text { vico Sforza nel Consiglio di Francia } \\
\text { per muovere il Re a far guerra a' Re } \\
\text { d'Aragona, che tenevano il Regno di } \\
\text { Napoli. }\end{array}$ \\
\hline
\end{tabular}

15. En el índice de la antología se identifica a Maquiavelo como el autor de esta sección. 
y en el libro 3 del dicho, la oración de los embajadores de Pisa pidiendo socorro a los venecianos; [p. 918] Orationi del terzo libro [di Paolo Giovio]. Orationi di M. Salvestro dal Poggio, ambasciador de' Pisani, fatta nel padiglione de' proveditori dell'esercito de' Venetiani, che erano all'assedio di Novara, chiedendo loro aiuto contra i Fiorentini. y la oración de Furio Camilo a los de Ardea solicitándolos a tomar las armas contra los franceses, que refiere Tito Livio, libro 5, década 3;
Orationi di Tito Livio raccolte dalle sue Historie di Roma ... [p. 464] Parlamento di Furio Camillo a gli Ardeati nel persuadergli a pigliar l'armi contra i Galli, i quali, havendo preso Roma, eccetto che il Campidoglio, venivano per pigliare ancora Ardea y el razonamiento de Terencio Varrón a los de Capua solicitándolos contra los cartagineses, que se lee en Livio, libro 3, década 3;
Orationi di Tito Livio raccolte dalle sue Historie di Roma ... [p. 515] Orationi del terzo libro della terza deca. Oratione di Terentio Varrone a gli Ambasciadori Capuani, i quali erano venuti a dolersi con lui della rotta ricevuta a Canne, nella quale il Consolo cerca di movergli a pigliar la guerra contra Annibale.

Orationi di Tito Livio raccolte dalle sue Historie di Roma ... [p. 561] Orationi del secondo libro della quarta deca. Ragionamento d'Aristeno, pretore de gli Achei nel consiglio, per muover il popolo a far lega co romani contra Filippo. 
y la oración del embajador de los hijos de Pompeyo a Marco Antonio persuadiéndole a tomar su proteción, porque con su ruina no creciese más el poder de Otaviano, su enemigo, es elegante discurso, y le refiere Apiano Alexandrino, libro 5;
Orationi militari d'Appiano Alessandrino, tratte da i cinque libri delle Guerre Civili ... Orationi del quinto libro ... [p. 320] Parole de gli ambaciadori di Pompeo, figliuolo di Pompeo Magno, a M. Antonio, persuadendolo a pigliar la sua protettione e difesa contra Ottaviano, mostrandogli che Ottaviano cercava di levarsi dinanzi Pompeo, accioché più facilmente potesse assalir M. Antonio, e gli lo manifesta con l'esempio di C. Cesare, il quale non tenne la fede a Pompeo, benché gli fusse genero, et entrati al conspetto d'Antonio, parlarono in questa foggia... y es gentil oración la del embajador de Corfú al senado de Atenas [f. 124] pidiendo socorro contra los de Corinto, referida por Tucídides, libro 1 . [p. 1] Orationi di Tucidide Ateniese, raccolte da gli otto libri delle guerre fatte tra gli Ateniesi e i popoli della Morea. Del libro primo. Oratione de gli ambasciadori di Corfù, fatta nel Senato de gli Ateniesi per movergli ad accetargli per confederati e dar loro aiuto nella guerra, che gli havevano contra i Corinthii.

2) Y cuando le ofrezca que un embajador, para encaminar al príncipe que asiste a sus intentos, trata de desvanecerle alguna opinión que tenga fundada en agüero o prodigio que haya aprehendido, o los miedos de alguna república o ejército fundados en esto mismo o en temor del poder del que se le desea dar por enemigo o en alguna batalla perdida u otro acidente doméstico, son dinas y forzosas de consultar las oraciones siguientes:

la de Hegesipo, que Herodes hace a su gente para inclinarlos a la batalla con los Árabes, libro 1; [p. 637] Orationi militari di Egesippo, historico christiano, raccolte da' cinque libri della Rovina di Hierusalem. Orationi del primo libro. Ragionamento d'Herode alle sue genti, nel dover venire al fatto d'arme con gli Arabi. 


\begin{tabular}{|c|c|}
\hline $\begin{array}{l}\text { y la de Totila, Rey Godo, a su gente, } \\
\text { libro } 3 \text { de la Historia de Procopio; }\end{array}$ & $\begin{array}{l}\text { Orationi militari di Procopio Cesa- } \\
\text { riense, raccolte dai tre libro dell'hi- } \\
\text { storie de' gothi ... [p. 709] Orationi } \\
\text { del terzo libro. Parole di Totila, re de' } \\
\text { Gothi, a' suoi soltadi, esortandogli a } \\
\text { sperar la vittoria del fatto d'arme con- } \\
\text { tra i Romani... }\end{array}$ \\
\hline $\begin{array}{l}\text { y la de César a su ejército, inclinándo- } \\
\text { lo a la guerra con los Franceses, des- } \\
\text { haciendo la opinión que dellos había } \\
\text { cobrado, referida por Dion, libro } 38 \\
\text { de su Historia romana; }\end{array}$ & $\begin{array}{l}\text { [p. 322] Orationi militari di Dione } \\
\text { Casio Niceno, tratte dalle sue Histo- } \\
\text { rie Romane ... Oratione di Cesare } \\
\text { ai suoi capitani, i quali s'eran messi } \\
\text { grandissimo spavento per havere a } \\
\text { combattere contra i Francesi... }\end{array}$ \\
\hline $\begin{array}{l}\text { y la de Cipión a su ejército, atemo- } \\
\text { rizado de ver de estotra parte de los } \\
\text { Alpes a Aníbal, que se lee en Polibio, } \\
\text { libro } 1 ;{ }^{16}\end{array}$ & $\begin{array}{l}\text { Orationi militari di Polibio, histori- } \\
\text { co Greco, raccolte da' sei libri delle } \\
\text { Guerre de' Romani contra le genti } \\
\text { forestiere. Del terzo libro ... [p. 260] } \\
\text { Breve esortatione di P. Scipione, con- } \\
\text { solo, a' suoi soltadi, i quali eran quasi } \\
\text { spaventati per la maraviglia del pas- } \\
\text { saggio d'Annibale di qua dall'Alpi... }\end{array}$ \\
\hline $\begin{array}{l}\text { y es admirable discurso que le lee en } \\
\text { Ascanio Centorio en su Historia de } \\
\text { Transilvania, libro 4, hecho por Juan } \\
\text { Bautista Castado a los transilvanos; }\end{array}$ & $\begin{array}{l}\text { Orationi militari di M. Ascanio Cen- } \\
\text { torio, tratte dai quattro libri della } \\
\text { Guerra di Transilvania ... [p. 977] } \\
\text { Orationi del quarto libro. Ripren- } \\
\text { sione del Castaldo a' principali di } \\
\text { Transilvania, che si erano spaventati } \\
\text { per una lettera minaciosa che'l Turco } \\
\text { havea scritto... }\end{array}$ \\
\hline
\end{tabular}

16. En Nannini aparece con las oraciones del libro tercero. 
y la oración de Furio Camilo a su ejército, que se lee en Livio, libro 6 , década 1 ;
Orationi di Tito Livio raccolte dalle sue Historie di Roma ... [p. 466] Orationi del sesto libro della prima deca. Ragionamento di Furio Camillo a i suoi soldati, che s'erano sbigottiti per la moltitudine e gran munmero de gli inimici. es elegante la oración de Aníbal a los cartagineses, que refiere el mismo, libro 1, década 3;
Orationi di Tito Livio raccolte dalle sue Historie di Roma ... Orationi del primo libro della terza deca et seconda guerra Cartaginese ... [p. 494] Oratione di Annibale a i soldati Cartaginesi, i quali per la stanchezza del viaggio, et per la rotta de i cavalli $\mathrm{Nu}$ midi havuta al Rodano da i cavalli Romani, e per la insolita altezza delle Alpi, s'erano sbigottiti.

y la de Otaviano a su gente [f. 124v] esortándolos a no enflaquecer por la multitud de naves de Marco Antonio, que escribe Dion, libro cincuenta, ${ }^{17}$
Orationi militari di Dione Casio Niceno, tratte dalle sue Historie Romane ... Orationi del cinquantesimo libro ... [p. 369] Parole di Ottavio alle sue genti d'arme, esortandola a non si sbigottire per la moltitudine delle navi d'Antonio.

[p. 401] Orationi militari di Giosefo tratte da' sette libri della Guerra Giudaica. Del primo libro. Oratione di Herode, re di Giudea, a' soldati Giudei dopo la rotta ricevuta da gli Arabi, i quali stavano paurosi e mesti, non tanto per la rotta quanto per alcuni terremoti, i quali essi stimavano esser venuti per giudicio di Dio.

17. En Nannini la oración aparece atribuida — correctamente- a Octavio, no a Octaviano.

18. En Nannini aparece identificada como del libro primero. 


\begin{tabular}{|c|c|}
\hline $\begin{array}{l}\text { y la oración de Vespasiano a su ejér- } \\
\text { cito, atemorizado de una batalla que } \\
\text { había perdido, que se lee en Josefo, } \\
\text { libro cuarto; }\end{array}$ & $\begin{array}{l}\text { Orationi militari di Giosefo tratte da' } \\
\text { sette libri della Guerra Giudaica ... } \\
\text { [p. 415] Orationi del quarto libro. } \\
\text { Parole di Vespasiano a' suoi soldati, i } \\
\text { quali eran grandemente sbigottiti per } \\
\text { una rotta ricevuta. }\end{array}$ \\
\hline $\begin{array}{l}\text { y es bien como suya la que pone Tu- } \\
\text { cídides en boca de Demóstenes, libro } \\
\text { cuarto de su historia; }\end{array}$ & $\begin{array}{l}\text { Orationi di Tucidide Ateniese, raccol- } \\
\text { te da gli otto libri delle guerre fatte } \\
\text { tra gli Ateniesi e i popoli della Morea } \\
\ldots \text { [p. 64] Orationi del quarto libro. } \\
\text { Parole di Demostene a i suoi soldati, } \\
\text { quali aspettavano l'assalto de' nemici, } \\
\text { ed erano alquanto impauriti per esse- } \\
\text { re inferiori di gente. }\end{array}$ \\
\hline $\begin{array}{l}\text { y la oración de Nicia a su gente, pavo- } \\
\text { rosa de la pérdida de su armada, que } \\
\text { refiere Tucídides, libro sétimo; }\end{array}$ & $\begin{array}{l}\text { Orationi di Tucidide Ateniese, raccol- } \\
\text { te da gli otto libri delle guerre fatte tra } \\
\text { gli Ateniesi e i popoli della Morea ... } \\
\text { [p. 104] Orationi del settimo libro. } \\
\text { Oratione di Nicia a i suoi soldati, i } \\
\text { quali havevano a fare l'estrema gior- } \\
\text { nata e si mostravano molto paurosi } \\
\text { per haver perduti molti fatti d'arme e } \\
\text { battaglie navali. }\end{array}$ \\
\hline $\begin{array}{l}\text { la de Aulo Póstumo Dictador, hecha a } \\
\text { su ejército, es llena de grandes conce- } \\
\text { tos y se lee en Dionisio Halicarnaseo, } \\
\text { libro sexto. }\end{array}$ & $\begin{array}{l}\text { Orationi militari di Dionisio Alicar- } \\
\text { naseo, tratte da gli undici libri del- } \\
\text { la sua Historia delle cose antichi di } \\
\text { Roma ... [p. 234] Orationi del sesto } \\
\text { libro. Oratione di Aulo Postumio, } \\
\text { dittatore, fatta all'esercito Romano } \\
\text { nel tempo che s'haveva a fare la gior- } \\
\text { nata co' Latini, esortandogli a non si } \\
\text { sbigottire per la moltitudine de' ne- } \\
\text { mici. }\end{array}$ \\
\hline
\end{tabular}


3) Pues para disuadir un embajador al príncipe asistido de la empresa que trata contra el propio o contra otro, diminuyéndole las causas en que la funda y ponderándole la resistencia que hallarán sus disinios, son elegantísimas oraciones:

la de Agripa al pueblo hebreo, que se lee en Hegesipo, libro 2;
Orationi militari di Egesippo, historico christiano, raccolte da' cinque libri della Rovina di Hierusalem ... [p. 641] Orationi del secondo libro. Oratione d'Agrippa a' Giudei, mostrando che le cagioni per lequali egli si movevano a far guerra co' Romani eran deboli e leggieri...

[p. 932] Orationi militari di monsignor Paulo Giovio, tratte dalla seconda parte dell'Historie de' suoi tempi. Del vigesimo ottavo libro. Oratione di Filippo del Migliore, persuadendo in publico consiglio la pace, e che si mandassero ambasciadori a Papa Clemente per trattarla.

y es admirable el parecer de Hanon, cartaginés, [f. 125] dado a su república, que se lee en Livio, libro tercero, década 3;
Orationi di Tito Livio raccolte dalle sue Historie di Roma ... Orationi del terzo libro della terza deca ... [p. 518] Oratione di Annone Cartaginese, dissuadendo il Senato a mandar gente e vettovoglia in Italia ad Annibale, ed esortandolo a non seguitar più la guerra contra i Romani. y el discurso de los embajadores de los citas a Alejandro es lleno de sentencias bellísimas, y lo escribe Quinto Curcio, libro sétimo;
Orationi militari di Quinto Curtio, tratte da' dieci libri de' Fatti d'Alessandro Magno ... Orationi del settimo libro ... [p. 622] Oratione d'uno ambasciadore de gli Scithi, bravando Alessandro che non ardisca entrare nel loro paese. 
y el consejo de Agripa al pueblo hebreo esortándolos a la paz con los romanos es singular, léese en Josefo, libro segundo;
Orationi militari di Giosefo tratte da' sette libri della Guerra Giudaica ... [p. 403] Orationi del secondo libro. Oratione bellissima di Agrippa ai Giudei, esortandogli per util loro a non pigliar guerra co’ Romani. y no menos bueno es el de Josefo al dicho pueblo hebreo, esortándolos a la misma paz, libro sexto De bello Iudaico;
Orationi militari di Giosefo tratte da' sette libri della Guerra Giudaica ... Orationi del sesto libro ... [p. 424] Oratione di Giosefo a' Giudei, esortandogli a rendersi a' Romani, mostrando che i loro peccati e Dio facevano loro guerra, non l'Imperio di Roma. y es elegante oración la del embajador de Atenas en el senado de Lacedemonia amonestándole no trabasen guerra con su república, que refiere Tucídides, libro primero;
Orationi di Tucidide Ateniese, raccolte da gli otto libri delle guerre fatte tra gli Ateniesi e i popoli della Morea. Del primo libro ... [p. 11] Oratione de gli ambasciadori Ateniesi nel consiglio de' Lacedemonii, per prohibire che eglino non pigliassero la guerra contra di loro... y la oración en dicho senado de Lacedemonia hecha por Archidamo, disuadiendo la guerra contra los atenienses, que también refiere Tucídides, libro primero;
Orationi di Tucidide Ateniese, raccolte da gli otto libri delle guerre fatte tra gli Ateniesi e i popoli della Morea. Del libro primo ... [p. 15] Oratione di Archidamo nel Senato de i Lacedemonii nel deliberare la guerra contra gli Ateniesi, laquale egli dissuase con molte ragioni. y no es menos elegante la de Artabano a Jerjes, disuadiéndole de la empresa de Grecia, que se lee en Heródoto, libro primero de su Historia de Persia $;^{19}$
Orationi d'Erodoto Alicarnaseo, raccolte da' nove libri delle Guerre de' Greci e de' Persiani. Del settimo libro, intitolato Polimnia ... [p. 113] Oratione di Artabano, zio di Xerse, dissuadendo il Re da questa guerra.

19. Nannini la sitúa en el libro primero. 
y superior a estas en piedad y viveza, la $\mathrm{X}$ del padre fray Bernardo de Fresneda, referida por Geronimo Conestagio, libro segundo de su Historia de las guerras de Germania.

4) [f. 125v] Y para persuadir un embajador a un príncipe (que tantas veces sucede) a no admitir la amistad de otro con quien no tiene paz el suyo, y a no darle paso por su tierra ni a entrar en liga con él, y últimamente a disponerle mortal enemigo suyo, son singulares las oraciones siguientes:

\begin{tabular}{|l|l|}
\hline $\begin{array}{l}\text { la de Cayo Mario al senado esortánd- } \\
\text { olo a la guerra contra Iugurta, que re- } \\
\text { fiere Salustio en Iugurta; }\end{array}$ & $\begin{array}{l}\text { Orationi militari di Crispo Salustio ... } \\
\text { Orationi della Guerra di Iugurta ... [p. } \\
594 \text { ] Oratione di Caio Memmio, tribu- } \\
\text { no della Plebe, fatta in Senato contra } \\
\text { Iugurta, nella quale egli esorta il popolo } \\
\text { a mover la guerra a Iugurta, e non la- } \\
\text { sciare invendicate le sue scelerità. }\end{array}$ \\
\begin{tabular}{|l} 
y la de Publio Cornelio al senado di- \\
lee en Apiano Alexandrino, libro 1 de
\end{tabular} & $\begin{array}{l}\text { Orationi militari d'Appiano Alessan- } \\
\text { drino, tratte dalla Historia delle guerre } \\
\text { esterne de' Romani. Della guerra carta- } \\
\text { ginese ... [p. 285] Oratione di Publio } \\
\text { Cornelio, fatta in Senato, per dissuader } \\
\text { la pace con i Cartaginesi, mostrando } \\
\text { con molte ragioni esser meglio distrug- } \\
\text { ger Cartagine che lasciarla in piedi, an- } \\
\text { cor che vinta e superata. }\end{array}$ \\
\hline $\begin{array}{l}\text { y es harto de leer la de Pastor, napo- } \\
\text { litano, contra Belisario, libro 1 de la } \\
\text { Historia de Procopio; }\end{array}$ & $\begin{array}{l}\text { [p. 697] Orationi militari di Procopio } \\
\text { Cesariense, raccolte dai tre libro dell'hi- } \\
\text { storie de' gothi. Del primo libro. Parole } \\
\text { di Pastore, gentil'huomo Napolitano, } \\
\text { fautor de' Gothi, fatte a' Napolitani, es- } \\
\text { sortandogli a non ricever Belisario nella } \\
\text { città di Napoli, dove egli era all'assedio, } \\
\text { perché stimandolo huomo di poca fede, } \\
\text { quantumque egli havesse fatte grandis- } \\
\text { sime promesse, dicea che non era da } \\
\text { credergli per esser mancato altre volte } \\
\text { delle sue parole... }\end{array}$ \\
\hline
\end{tabular}

20. La oración al senado a la que se refiere Vera es la de Cayo Memmio; la pronunciada por Cayo Mario fue dirigida al pueblo (Nannini la recoge en la p. 597). 


\begin{tabular}{|c|c|}
\hline $\begin{array}{l}\text { y no menos elegante, la de Neri Capo- } \\
\text { ni, florentín, en el senado de Venecia, } \\
\text { la cual se lee en el libro } 5 \text { de la Historia } \\
\text { florentina; }\end{array}$ & $\begin{array}{l}\text { Orationimilitaritrattedagliottolibridel- } \\
\text { le Historie di Fiorenza }{ }^{21} \ldots \text { Orationi del } \\
\text { quinto libro ... [p. } 873 \text { ] Oratione di Neri } \\
\text { di Gino Capponi nel Senato di Vene- } \\
\text { tia, offerendo a' Venetiani da parte de' } \\
\text { Fiorentini soccorso grandissimo per la } \\
\text { guerra che havevano co'l Duca di Mi- } \\
\text { lano. }\end{array}$ \\
\hline $\begin{array}{l}\text { y la oración de Tribulcio al ejército } \\
\text { francés, que refiere Jovio, libro } 2 \text {; }\end{array}$ & $\begin{array}{l}\text { Orationi militari di monsignor Pau- } \\
\text { lo Giovio, tratte dalla prima parte } \\
\text { dell'Historie de' suoi tempi ... Ora- } \\
\text { tioni del secondo libro ... [p. 913] } \\
\text { Oratione del Trivvultio all'esercito } \\
\text { Francese, esortandolo a farsi la via con } \\
\text { l'arme, e non venire co' nimici ad alcu- } \\
\text { no accordo. }\end{array}$ \\
\hline $\begin{array}{l}\text { y es elegante el razonamiento del em- } \\
\text { bajador de Filipo en el senado etolio; }\end{array}$ & $\begin{array}{l}\text { Orationi di Tito Livio raccolte dalle } \\
\text { sue Historie di Roma ... Orationi del } \\
\text { primo libro della quarta deca ... [p. } \\
\text { 557] Ragionamento d'un ambasciado- } \\
\text { re del Re Filippo nel consiglio de gli } \\
\text { Etoli, persuadendogli a non si partir } \\
\text { dalla lega di Filippo. }\end{array}$ \\
\hline $\begin{array}{l}\text { y no menos el del embajador romano } \\
\text { en el mismo senado, opuestros el uno } \\
\text { al otro, y ambos referidos de Livio, li- } \\
\text { bro 1, década 4; }\end{array}$ & $\begin{array}{l}\text { Orationi di Tito Livio raccolte dalle } \\
\text { sue Historie di Roma ... Orationi del } \\
\text { primo libro della quarta deca ... [p. } \\
559 \text { ] Risposta de' Romani nel mede- } \\
\text { simo consiglio e dieta de gli Etoli, per } \\
\text { far ch'ei lasciassero la pace con Filippo } \\
\text { e pigliassero con loro la guerra contra } \\
\text { di lui... }\end{array}$ \\
\hline $\begin{array}{l}\text { y debe consultarse en este caso la ora- } \\
\text { ción de los legados de Corinto disua- } \\
\text { diendo al senado la confederación y } \\
\text { socorro que le pedían los de Corfú, que } \\
\text { refiere Tucídides. }\end{array}$ & $\begin{array}{l}\text { Orationi di Tucidide Ateniese, raccol- } \\
\text { te da gli otto libri delle guerre fatte tra } \\
\text { gli Ateniesi e i popoli della Morea. Del } \\
\text { primo libro ... [p. 4] Risposta de gli } \\
\text { ambasciadori di Corinto nel consiglio } \\
\text { de gli Ateniesi per dissuadergli dalla } \\
\text { confederatione de' Corfiotti, alla quale } \\
\text { parevano molto inchinati. }\end{array}$ \\
\hline
\end{tabular}

21. En el índice de la antología se identifica a Maquiavelo como el autor de esta sección. 
5) Pues para disculpar con generosidad el no haber dado ayuda en alguna ocasión al príncipe, que en [f. 126] la presente se desee satisfacer y congratular, es superior discurso:

el que Herodes ordena hablando con César Augusto, que refiere Hegesipo, libro 1;
Orationi militari di Egesippo, historico christiano, raccolte da' cinque libri della Rovina di Hierusalem. Orationi del primo libro ... [p. 639] Parole d'Herode a Cesare Augusto dopo che egli hebbe rotto Marco Antonio e Cleopatra, nelle quali egli, ritenendo una invitta generosità d'animo, dimostra che se ei non ha dato aiuto a Marco Antonio contra di lui, è stato per non haver potuto, e che vuol più tosto confessar liberamente d'esser stato nimico di Cesare che ingrato all'amico... y la oración de Lucio Antonio a su ejército asgurándole alcanzarles la paz de Otaviano, aunque la compre a precio de su sangre, que refiere Apiano Alexandrino, libro 5.
Orationi militari d'Appiano Alessandrino, tratte da i cinque libri delle Guerre Civili ... Orationi del quinto libro ... [p. 317] Ragionamento di Lucio Antonio a' suoi soldati, promettendo loro di far pace con Ottaviano, e non potendo impetrarla altrimenti, ottenerla con la sua propria morte.

6) Y para empeñar a un príncipe en la amistad de otro, aunque la infelicidad de ambos sea manifiesta, y saborearle en el gusto del peligro y disponerle a querer la muerte antes que pedir piedad o cosas deste conceto, hallará mucho de qué valerse el embajador consultando en:

Hegesipo, libro 3, la oración de un soldado a Josefo;
Orationi militari di Egesippo, historico christiano, raccolte da cinque libri della Rovina di Hierusalem ... [p. 648] Orationi del terzo libro. Parole d'un soldato a Giosefo, esortando ad uccider se stesso prima che venir vivo nelle mani de' Romani... 


\begin{tabular}{|c|c|}
\hline $\begin{array}{l}\text { y la de Matías a su hijo en el mismo } \\
\text { autor, libro 5; }\end{array}$ & $\begin{array}{l}\text { Orationi militari di Egesippo, histori- } \\
\text { co christiano, raccolte da' cinque libri } \\
\text { della Rovina di Hierusalem ... Ora- Ora } \\
\text { tioni del quinto libro ... [p. 667] Pie- } \\
\text { toso ragionamento di Mattia a' suoi } \\
\text { figliuoli prima ch'ei fosse amazzato } \\
\text { dal boia... }\end{array}$ \\
\hline $\begin{array}{l}\text { y la de Eleazaro a su ejército, en dicho } \\
\text { autor y libro; }\end{array}$ & $\begin{array}{l}\text { Orationi militari di Egesippo, histo- } \\
\text { rico christiano, raccolte da' cinque } \\
\text { libri della Rovina di Hierusalem ... } \\
\text { Orationi del quinto libro ... [p. } 679 \text { ] } \\
\text { Oratione d'Eleazaro a' suoi, esortan- } \\
\text { dogli ad uccider le mogli, le madri, i } \\
\text { figliuoli e se stessi, prima che venire } \\
\text { nelle mani de' nemici... }\end{array}$ \\
\hline $\begin{array}{l}\text { y la de un famoso caballero daciano } \\
\text { a Frotone, su rey, que refiere Sasón } \\
\text { Gramático, libro } 2 \text { de la Historia de } \\
\text { Dacia; }\end{array}$ & $\begin{array}{l}\text { Orationi militari di Sassone Gram- } \\
\text { matico, tratte da i quindici libri della } \\
\text { Historie della Dacia. Del secondo li- } \\
\text { bro ... [p. } 720 \text { ] Parole d'un cavalier } \\
\text { di Dacia al suo Re, mostrando esser } \\
\text { cosa più honorata morir con la preda } \\
\text { in mano che abandonarla per paura. }\end{array}$ \\
\hline $\begin{array}{l}\text { y la del legado del Papa al ejército ca- } \\
\text { tólico de Asia, que escribe Benedito } \\
\text { Aretino, libro } 3 \text { de la Historia de la } \\
\text { Tierra Santa; }\end{array}$ & $\begin{array}{l}\text { Orationi militari di Benedetto Ac- } \\
\text { colti, Aretino, tratte da' quattro Libri } \\
\text { della Guerra fatta da' Christiani con- } \\
\text { tra i Barbari per la ricuperatione del } \\
\text { Sepolcro di Christo e della Giudea ... } \\
\text { Orationi del terzo libro ... [p. } 851] \\
\text { Oratione del legato del Papa a tutto } \\
\text { l'esercito, dovendosi in termine di } \\
\text { tre giorni fare la giornata con i Per- } \\
\text { siani, perché se non si veniva al fatto } \\
\text { d'arme, i Christiani eran forzati per la } \\
\text { fame a rendersi con lor gran vituperio. }\end{array}$ \\
\hline
\end{tabular}

22. El «Benedito Aretino» que cita Vera es Benedetto Accolti. 
y la de Florio esortando antes a dejar la ciudad que sujetarse al turco, que refiere el autor del libro de La guerra de los turcos y cristianos, libro 1 ;
Orationi militari tratte da' libri dell'Istorie delle guerre de' Turchi contra i Christiani, e de' Christiani contra loro ... [p. 998] Oratione di Florio Scodrese, esortando i cittadini a partirsi della città, più tosto che venire sotto la fede e governo del Turco. es muy de considerar la de Vibio, capuano, en su senado, referida por Livio, libro 3;
Orationi di Tito Livio raccolte dalle sue Historie di Roma ... [p. 531] Orationi del sesto libro della terza deca. Oratione di Vibio Virrio, Capuano, nel Senato, esortandolo a non si rendere a i Romani, temendo della loro crudeltà, mostrando esser meglio morire che venire nelle loro mani. y la de Bocola a sus soldados, que refiere Tácito, libro 20;
Orationi militari di Cornelio Tacito, tratte da' venti libri dell'Historie de' Romani ... [p. 381] Orationi del ventesimo libro. Parole di Vocola a' suoi soldati, il quale, ritrovandosi assediato da' Galli, era esortato a fuggirsi; ma egli, che voleva far più tosto una honorata morte che una vergognosa fuga, ancor ch'egli havesse inteso che i soldati l'harebbero ucciso, nondimeno per mantener i soldati in fede e per fargli più animosi, chiamatigli, parlò loro...

Orationi militari di Giosefo tratte da' sette libri della Guerra Giudaica ... Orationi del settimo libro ... [p. 434] Oratione bellissima di Eleazaro, esortando i suoi soldati i suoi ad uccidere le mogli, i figliuoli e loro stessi, poi che non potevano scampare da' Romani... 
y la de Terición a Cleomeno, que refiere en su Vida Plutarco.
Orationi militari di Plutarco, cavate dalle sue Vite ... [p. 443] Della Vita di Cleomene. Parole di Tericione a Cleomene, esortandolo a uccider se stesso, per non veder le vergogne che soglion veder coloro che non stati rotti in battaglia.

7) Para conseguir un embajador que el príncipe o república que, con algunos intentos se apartó de la amistad de su Rey, se reduzga a ella y se contente con la fortuna que gozaba, sin aspirar a novedad peligrosa, es escelente discurso:

\begin{tabular}{|c|c|}
\hline $\begin{array}{l}\text { el que Josefo hace a los judíos, libro } 5 \\
\text { de Hegesipo; }\end{array}$ & $\begin{array}{l}\text { Orationi militari di Egesippo, histo- } \\
\text { rico christiano, raccolte da cinque } \\
\text { libri della Rovina di Hierusalem ... } \\
\text { Orationi del quinto libro ... [p. 659] } \\
\text { Esortatione di Giosefo a' Giudei, per- } \\
\text { suadendogli a pigliar la benignità de' } \\
\text { Romani, e mostrando loro che, non } \\
\text { essendo mai per tempo alcuno stati } \\
\text { liberi, non dovevan così pertinace- } \\
\text { mente difender la libertà senza haver } \\
\text { riguardo al Tempio e all'altre cose sa- } \\
\text { cre... }\end{array}$ \\
\hline $\begin{array}{l}\text { y la oración de Minucio, embajador } \\
\text { romano, a Marco Coriolano esortán- } \\
\text { dolo a dejar los bloscos y volverse a } \\
\text { su patria Roma, que refiere Dionisio } \\
\text { Halicarnaseo, libro } 8 \text {. }\end{array}$ & $\begin{array}{l}\text { Orationi militari di Dionisio Alicar- } \\
\text { naseo, tratte da gli undici libri del- } \\
\text { la sua Historia delle cose antichi di } \\
\text { Roma ... Orationi del ottavo libro ... } \\
\text { [p. 245] Oratione di Minutio, amba- } \\
\text { sciadore de' Romani, mandato a Mar- } \\
\text { tio per trattar la pace, e sua ritornata } \\
\text { in Roma, e del levar la guerra. }\end{array}$ \\
\hline
\end{tabular}


8) El embajador que tratare de desculpar el Rey que asiste cualquiera queja que tenga del suyo por agravio hecho a su fe o a sus vasallos o por otro respecto de Estado, consulte atentamente:

la oración que Donato Barbadori hizo al pontífice Gregorio, que se lee en el $8^{\circ}$ libro de Leonardo Aretino de la Historia de Florencia;
Orationi militari tratte da gli otto libri delle Historie di Fiorenza ... [p. 753] Orationi del ottavo libro. Oratione di Donato Barbadori, ambasciadore de' Fiorentini a Papa Gregorio fatta a sua Santità per mostrare che le cagioni della ribellione e della guerra contra i suoi legati in Italia era nata dal cattivo governo loro, e non da' Fiorentini.

y la que desta misma ación refiere el Pogio, autor florentín, en su libro $1 ;^{23}$
Orationi militari del Poggio Fiorentino, raccolte da gli otto libri delle sue Historie di Fiorenza. Del secondo libro ... [p. 778] Oratione di Donato Barbadori a Papa Gregorio, fatta per difesa de popol Fiorentino, il quale havea preso l'arme contra la Chiesa. E benché l'Aretino (si come detto poco di sopra) tocchi questa medesima materia e introduca a ragionare il medesimo Barbadori, nondimeno per esser l'oratione del Poggio abondantissima di sentenze e di bellissimi colori retorici, non habbiamo voluto mancare di metterla in compagna dell'altre, benché io non sappia chi di questi due scrittori s'havesse la vera... y la que Astimaco, embajador de la ciudad de Platea, hizo en Lacedemonia, que se lee en Tucídides, libro $1 .^{24}$
Orationi di Tucidide Ateniese, raccolte da gli otto libri delle guerre fatte tra gli Ateniesi e i popoli della Morea ... Orationi del terzo libro ... [p. 55] Ragionamento di Astimaco, ambasciadore della città di Platea, fatto alla presenza de i giudici Lacedemoni, pregandogli che ancora che la città si fosse arresa per forza, non dovessero però usar crudeltà verso di loro.

23. Nannini la registra dentro de libro segundo.

24. En Nannini aparece con las oraciones del libro segundo. 
9) Y el embajador que tuviere orden del Rey de reservarle la liga antigua con pretesto de alguna [f. 127] ocasión aparente, debe ayudar su intento de:

la oración que los de Bolonia hicieron en el senado de Florencia;
Orationi di Lionardo Aretino, tratte da' dodici libro dell'Historie di Fiorenza ... [p. 763] Orationi del decimo libro. Ragionamento breve degli ambasciadori di Bologna nel Consiglio di Fiorenza chiedendo a' Fiorentini o danari per mantener la guerra o licenza di poter far pace co'l nimico, in quel modo più honesto che potevano, perché Galeazzo, Duca di Milano, gli haveva molto affaticato con la continua guerra dalla quale i Bolognesi eran molto desiderosi di liberarsi...

y aun de la respuesta que les dieron, que refiere Leonardo Aretino, libro 10 ;
Orationi militari tratte da gli otto libri delle Historie di Fiorenza ... Orationi del decimo libro ... [p. 764] Risposta de' Fiorentini a gli oratori Bolognesi, mostrando esser meglio per loro continuar nella guerra che venire co'l nimico a una honesta pace...

Orationi di Tucidide Ateniese, raccolte da gli otto libri delle guerre fatte tra gli Ateniesi e i popoli della Morea ... Orationi del sesto libro ... [p. 94] Oratione di Hermocrate ai Camarinei per movergli a romper la lega de gli Ateniesi e pigliar l'armi contra di loro in compagnia de' Siracusani, de' quali erano medesimamente confederati. 
10) El embajador que para alguna causa común (y más si es de religión o piedad) tratare de reducir a algún príncipe, república o pueblo a su opinión, no olvide:

la oración del papa Urbano a los príncipes cristianos esortándolos a la conquista de Tierra Santa, que refiere Marco Antonio Sabelico, libro 5, década 1, de la Historia de Venecia; [p. 786] Orationi militari di Marco Antonio Sabellico tratte dalle tre deche della historie di Venetia. Del quinto libro della prima deca. Oratione di Papa Urbano a' principi Christiani, esortandogli a pigliar l'armi per lo racquisto ti terra Santa, che era occupada da' Turchi, e allhora si bandì la Crociata. y otra del Corio en el libro 1 de su historia; [p. 829] Orationi militari di M. Bernardino Corio, nobile Milanese, raccolte da' sette libri delle sue Historie di Milano. Del primo libro. Oratione di Federigo Imperadore, fatta dinanzi a' principi del suo consiglio e capitani dell'esercito, deliberando di rovinar Milano. y la que en cabeza del cardenal Marino, hecha al César Carlos Quinto, refiere Jovio, libro $3 ;^{25}$
Orationi militari di monsignor Paulo Giovio, tratte dalla prima parte dell'Historie de' suoi tempi ... [p. 949] Orationi del quarantesimo terzo libro. Oratione del Cardinal Marino Grimani fatta all'Imperadore sopra la pace col Re di Francia, alla quale non l'haveva potuto piegare Papa Paolo Terzo... y es de notar la oración de Bruto solicitando el pueblo contra Tarquino, que refiere Dionisio Halicarnaseo, libro 4.
Orationi militari di Dionisio Alicarnaseo, tratte da gli undici libri della sua Historia delle cose antichi di Roma ... [p. 229] Orationi del quarto libro. Oratione di Bruto al popolo Romano per muoverlo a pigliar l'armi contra Tarquino e far vendetta della violenza e morte di Lucretia, il corpo della quale era quivi presente in una bara, tutto insanguinato.

25. Es del libro 43, según Nannini. 
11) Para persuadir a una guerra es notable oración:

la que el Sabelico pone en cabeza de Francisco Foscari, duque de Venecia, en el libro 9, década 2;
Orationi militari di Marco Antonio Sabellico tratte dalle tre deche della historie di Venetia ... Orationi del nono libro della seconda deca ... [p. 801] Oratione di Francesco Foscari, LXV Doge di Venetia, fatta in Senato, per muoverlo a cominciar la guerra contra Filippo, Duca di Milano. y la del embajador genovés a Carlo VIII, rey de [f. 127v] Francia, que refiere Paulo Emilio, libro 9; 26
Orationi militari di Paolo Emilio da Verona, tratte da dieci libri delle Cose di Francia ... Orationi del nono libro ... [p. 826] Ragionamento de gli ambasciadori Genovesi alla presenza di Carlo VI, Re di Francia, esortandolo a ripigliar la guerra contra gli infideli, che i suoi antichi havevan cominciata. y es dino de leerse el razonamiento que hace Pinamonte a varios embajadores, que refiere el Corio, libro 1;
Orationi militari di M. Bernardino Corio, nobile Milanese, raccolte da' sette libri delle sue Historie di Milano. Del primo libro ... [p. 831] Ragionamento di Pinamonte Vimercato, fatta nella chiesa di San Iacopo in Pontida nel Bresciano, dove eran concorsi molti ambasciadori delle città di Lombardia, per persuadergli a ribellarsi da Federigo e a rifar Milano... y es bien razonada en estremo la oración que hace un gentilhombre luqués en su senado, que se lee en la Historia de Florencia, libro 5;
Orationi militari tratte da gli otto libri delle Historie di Fiorenza ... Orationi del quinto libro ... [p. 870] Ragionamento d'un gentil'huomo Lucchese, fatto al popolo di Lucca per eccitarlo a difender la città contra i Fiorentini.

26. Nannini da a Carlos VI como destinatario de este discurso. 


\begin{tabular}{|c|c|}
\hline $\begin{array}{l}\text { y la de Apio Claudio hecha al pueblo } \\
\text { contra los tribunos escrita por Livio, } \\
\text { libro } 4 \text {, década } 1 ;^{27}\end{array}$ & $\begin{array}{l}\text { Orationi di Tito Livio raccolte dalle } \\
\text { sue Historie di Roma ... Orationi } \\
\text { del quinto libro della prima deca ... } \\
\text { [p. 458] Oratione di Appio Claudio, } \\
\text { fatta al popolo contra i Tribuni de- } \\
\text { lla Plebe, confortandolo a seguitar la } \\
\text { guerra Veientana. }\end{array}$ \\
\hline $\begin{array}{l}\text { y es memorable la de un embajador } \\
\text { de Corinto en el senado de Lacede- } \\
\text { monia para solicitarle contra los ate- } \\
\text { nienses que refiere Tucídides, libro } 1 \text {; }\end{array}$ & $\begin{array}{l}\text { Orationi di Tucidide Ateniese, raccol- } \\
\text { te da gli otto libri delle guerre fatte tra } \\
\text { gli Ateniesi e i popoli della Morea ... } \\
\text { Del primo libro ... [p. 8] Parlamento } \\
\text { de gli ambasciadori di Corinto nel Se- } \\
\text { nato de i Lacedemoni, per muovergli } \\
\text { alla guerra contra gli Ateniesi. }\end{array}$ \\
\hline $\begin{array}{l}\text { y elegante la de Alcibíades respon- } \\
\text { diendo a otra de Nicio en el senado de } \\
\text { Atenas esortándolo a la guerra en Si- } \\
\text { cilia, que se lee en Tucídides, libro 6; }\end{array}$ & $\begin{array}{l}\text { Orationi di Tucidide Ateniese, raccol- } \\
\text { te da gli otto libri delle guerre fatte tra } \\
\text { gli Ateniesi e i popoli della Morea ... } \\
\text { Orationi del sesto libro ... [p. 83] Ra- } \\
\text { gionamento d'Alcibiade rispondendo } \\
\text { alle parole di Nicia, e persuadendo gli } \\
\text { Ateniesi a questa impresa della Sicilia, } \\
\text { con molte ragioni. }\end{array}$ \\
\hline $\begin{array}{l}\text { y la de Vitorio Capelo en el senado } \\
\text { veneciano esortando a la guerra con el } \\
\text { turco, que refiere el autor del libro de } \\
\text { Guerras de turcos y cristianos; }\end{array}$ & $\begin{array}{l}\text { [p. 995] Orationi militari tratte da' } \\
\text { libri dell'istorie delle Guerre de' Tur- } \\
\text { chi contra i Christiani, e de' Christia- } \\
\text { ni contra loro. Oratione di Vittorio } \\
\text { Cappello nel Senato Venetiano, esor- } \\
\text { tando la guerra contra il Turco. }\end{array}$ \\
\hline $\begin{array}{l}\text { y la de Cortugolo cosario disponien- } \\
\text { do a Solimán a la empresa de Rodas, } \\
\text { libro } 1 \text { de las dichas Guerras; }\end{array}$ & $\begin{array}{l}\text { Orationi militari tratte da' libri dell'i- } \\
\text { storie delle Guerre de' Turchi contra i } \\
\text { Christiani, e de' Christiani contra lo- } \\
\text { ro ... [p. 1.002] Ragionamento di } \\
\text { Cortugolo, corsaro, a Solimano, Re } \\
\text { de' Turchi, esortandolo all'impresa di } \\
\text { Rodi. }\end{array}$ \\
\hline
\end{tabular}

27. Identificada en Nannini como perteneciente a la década primera, libro quinto. 
y es admirable la de Tito Quincio a los romanos, que refiere Livio, libro 3 , década 1 .
Orationi di Tito Livio raccolte dalle sue Historie di Roma ... Orationi del terzo libro della prima deca ... [p. 454] Oratione di Tito Quintio Capitolino, fatta al popolo Romano, per farlo pigliar l'armi contra gli Equi e i Volsci, che erano scorsi predando fino su le porte di Roma.

12) Para facilitar una empresa ardua, sea militar o civil, y contrastar la opinión que la disuade, encargara yo a todo embajador que la tuviese a su cuidado que leyese:

la oración de que Carlo Martelo hace a su gente, que refiere Paulo Emilio, libro 2 de su Historia de Francia; [p. 804] Orationi militari di Paolo Emilio da Verona, tratte da' dieci libri delle Cose di Francia. Del secondo libro. Ragionamento di Carlo Martello, Principe della Francia, a' suoi soldati, i quali dovevan far fatto d'arme co' Saracini, che erano in tanto gran numero che superavano i Francesi quasi in dieci doppi, e con tutto questo non si mostravano paurosi.

Orationi militari di monsignor Paulo Giovio, tratte dalla seconda parte dell'Historie de' suoi tempi ... Del trentesimo libro ... [p. 937] Oratione di Barba Rossa a Solimano sopra il muovere e deliberare della guerra Africana, alla quale egli era molto inchinato.

28. Según Nannini es del libro 30. 


\begin{tabular}{|c|c|}
\hline $\begin{array}{l}\text { y es, aunque breve, ilustre, la del mar- } \\
\text { qués del Basto, embajador imperial en } \\
\text { Venecia, que refiere Jovio, libro 39; }\end{array}$ & $\begin{array}{l}\text { Orationi militari di monsignor Pau- } \\
\text { lo Giovio, tratte dalla seconda parte } \\
\text { dell'Historie de' suoi tempi ... [p. 942] } \\
\text { Orationi del trentesimo nono libro. } \\
\text { Parole del Marchese del Vasto, am- } \\
\text { basciador dell'Imperadore, fatte alla } \\
\text { Signoria di Venetia per tirargli alla lega } \\
\text { del Re di Francia e dell'Imperadore, } \\
\text { i quale havevan fatto pace insieme... }\end{array}$ \\
\hline $\begin{array}{l}\text { y la de Druparo, rey de los godos a } \\
\text { su reino, que se lee en el libro } 3 \text { del } \\
\text { Origen de los bárbaros; }\end{array}$ & $\begin{array}{l}\text { [p. 985] Orationi militari tratte da } \\
\text { gli undici libri dell'historie intitolate } \\
\text { Origine de' Barbari. Del terzo libro. } \\
\text { Oratione di Druparo, Re de' Goti, } \\
\text { fatta in una dieta a' suoi baroni, per } \\
\text { deliberare la guerra contra i Romani. }\end{array}$ \\
\hline $\begin{array}{l}\text { y la de Fridigerno, rey de los ostrogo- } \\
\text { dos, a sus capitanes, que se lee en el } \\
\text { dicho tomo, libro } 5 ;^{29}\end{array}$ & $\begin{array}{l}\text { Orationi militari tratte da gli undici } \\
\text { libri dell'historie intitolate Origine } \\
\text { de' Barbari ... [p. 988] Orationi del } \\
\text { quarto libro. Oratione di Frigiderno, } \\
\text { Re degli Ostrogogi a' suoi capitani, } \\
\text { esortandogli a muover guerra all'Im- } \\
\text { perio Romano. }\end{array}$ \\
\hline $\begin{array}{l}\text { y es rarísima la oración de Carlo } \mathrm{V} \text {, } \\
\text { que refiere Gerónimo Faleti en sus } \\
\text { Comentarios; }\end{array}$ & $\begin{array}{l}\text { [p. 957] Orationi militari di Girola- } \\
\text { mo Faleti, tratte da gli otto libro della } \\
\text { Guerra di Lamagna. Del primo libro. } \\
\text { Parole dell'Imperadore a coloro che lo } \\
\text { dissuadevano a romper la guerra con- } \\
\text { tra Filippo Langravio. }\end{array}$ \\
\hline $\begin{array}{l}\text { y la que el dicho autor pone en cabe- } \\
\text { za del duque de Sajonia en el mismo } \\
\text { libro; }\end{array}$ & $\begin{array}{l}\text { Orationi militari di Girolamo Faleti, } \\
\text { tratte da gli otto libro della Guerra } \\
\text { di Lamagna. Del primo libro ... [p. } \\
\text { 959] Parole di Gio. Federigo, Duca di } \\
\text { Sassonia a coloro che lo persuadevano } \\
\text { a non pigliar la guerra contra l'Impe- } \\
\text { radore... }\end{array}$ \\
\hline
\end{tabular}

29. Del libro cuarto, según Nannini. 
pero como singular encargo la de Marcio Coriolano esortando a los blosquos a la guerra con Roma y facilitándoles el suceso, refiérela Dionisio Halicarnaseo, libro 8;
Orationi militari di Dionisio Alicarnaseo, tratte da gli undici libri della sua Historia delle cose antichi di Roma ... [p. 241] Orationi del ottavo libro. Oratione di Martio Coriolano a' Volsci, esortandogli alla guerra contra i Romani, e mostrando con quale agevolezza si poteva abbassare la grandezza di Roma.

y no sé si tenga por superior la que $\mathrm{X}$ Gerónimo Conestagio atribuye a don Fernando Álvarez de Toledo, duque de Alba, en el consejo de estado de Castilla, libro 2 de su Historia de la inferior Germania.

13) Pues para informar un embajador a un tercero príncipe para que medie entre las diferencias de dos, pierda un rato y lea:

la oración del embajador de Inglaterra hecha al Emperador, que refiere Paulo Emilio, libro 9 de la Historia de Francia;
Orationi militari di Paolo Emilio da Verona, tratte da' dieci libri delle Cose di Francia ... Orationi del nono libro ... [p. 819] Orationi de gli ambasciadori Inglesi, fatta dinanzi all'Imperadore, per muoverlo a procurar di reintegrare la pace tra i Francesi e gli Inglesi, la quale era stata rotta, ne si sapeva bene chi fosse stato il primo. y la que en contrario desta hace el embajador francés en el mismo lugar;
Orationi militari di Paolo Emilio da Verona, tratte da' dieci libri delle Cose di Francia ... Orationi del nono libro ... [p. 822] Risposta de gli oratori Francesi, i quali, trovatisi alla presenza de' duoi Imperadori parenti del loro Re, e sentendo le querele de gli Inglesi, per difesa delle loro ragioni, fu fatto dal primo di loro questa risposta. 
y la oración de Metio a Tulo Hostilio, que refiere Livio, libro 1. [p. 447] Orationi di Tito Livio raccolte dalle sue Historie di Roma. Del primo libro della prima deca. Parole di Metio Suffetio, capitano de gli Albani, a Tullo Hostilio, Re de' Romani, per compor la pace tra i Romani e gli Albani.

14) [f. 128v] Para indinar un rey, senado o ejército contra alguna nación, el embajador que lo procura válgase de:

la oración de Cleón, ateniense, en su senado contra los de Mitilene.
Orationi di Tucidide Ateniese, raccolte da gli otto libri delle guerre fatte tra gli Ateniesi e i popoli della Morea ... Orationi del terzo libro ... [p. 47] Parlamento di Cleone, Ateniese, nel Senato d'Atene, esortando a castigare i Mitilenei, che s'erano ribellati senza cagione e havevan mosso guerra ingiusta, della quale e' furono perdenti.

15) Y para disculpar un delito y suspender una determinación grande es dina de leerse:

la que en contrario de esta oración de Cleón se respondió, que ambas las refiere Tucídides en el libro 1 de su historia. ${ }^{30}$
Orationi di Tucidide Ateniese, raccolte da gli otto libri delle guerre fatte tra gli Ateniesi e i popoli della Morea ... Orationi del terzo libro ... [p. 51] Oratione di Diodoto, Ateniese, in difesa de' Mitilenei, e contraria alla crudele opinione dei Cleone, che voleva che fossero morti tutti i popoli della città.

30. En Nannini aparece con las oraciones del libro segundo. 
16) Para sustentar un embajador la provincia que asiste rey o república en una opinión y hacella sospechosa en lo que él más teme y mantener un príncipe en valor, aunque haya padecido alguna rota, es valiente oración:

la de Próspero Colona a los aragoneses, que refiere Jovio, libro 3;
Orationi militari di monsignor Paulo Giovio, tratte dalla prima parte dell'Historie de' suoi tempi ... Orationi del terzo libro ... [p. 921] Ragionamenti di Prospero Colonna a gli Aragonesi, mostrando che benché si fosse havuto una rotta, non si doveva per questo cedere alla Fortuna. y la que pone Gerónimo Faleti en cabeza de Lanzgrave, libro 2, de su Historia de Alemania;
Orationi militari di Girolamo Faleti, tratte da gli otto libro della Guerra di Lamagna ... [p. 960] Del secondo libro. Ragionamento di Filippo Lantgravi a' suoi capitani, esortandogli a esser buoni difensori della loro propria libertà e di tutta Lamagna, la quale pareva che volesse occupare l'Imperadore sotto coperta di voler castigare il Duca di Sassonia e Filippo Lantgravio...

Orationi militari tratte da gli undici libri dell'historie intitolate Origine de' Barbari ... [p. 992] Orationi del sesto libro. Ragionamento di Gilimer, re de' Vandli, all'Imperadore di Constantinopoli, mostrando che se bene in battaglia egli have perduto l'esercito, ed egli era stato fatto prigione, non haveve però perduto la grandezza dell'animo. y admirable la de Cornelio Tácito, libro 17 , que hace Pisón a los soldados de la guarda de Galba;
Orationi militari di Cornelio Tacito, tratte da' venti libri dell'Historie de' Romani ... [p. 376] Del decimosettimo libro. Ragionamento di Pisone a i soldati della guardia del palazzo di Galba, nel quale esorta i soldato a difender la ragione di Galba... 


\begin{tabular}{|c|c|}
\hline $\begin{array}{l}\text { y muy para ser leída es la de Cinemo, } \\
\text { capitán de la Morea a sus soldados, } \\
\text { afligidos de una rota de mar, que refie- } \\
\text { re Tucídides, libro } 1 \text { de su Historia }{ }^{31}\end{array}$ & $\begin{array}{l}\text { Orationi di Tucidide Ateniese, raccol- } \\
\text { te da gli otto libri delle guerre fatte tra } \\
\text { gli Ateniesi e i popoli della Morea ... } \\
\text { Orationi del secondo libro ... [p. 39] } \\
\text { Esortatione di Cinemo a' soldati della } \\
\text { Morea, i quali, impauriti per una rot- } \\
\text { ta ricevuta in mare, non volevan piû } \\
\text { combattere in battaglia navale. }\end{array}$ \\
\hline $\begin{array}{l}\text { y elegante discurso hace Tito Largio al } \\
\text { pueblo romano, que refiere Dionisio } \\
\text { Halicarnaseo, libro } 6 \text { de su Historia } \\
\text { romana. }\end{array}$ & $\begin{array}{l}\text { Orationi militari di Dionisio Alicar- } \\
\text { naseo, tratte da gli undici libri del- } \\
\text { la sua Historia delle cose antichi di } \\
\text { Roma ... Orationi del sesto libro ... } \\
\text { [p. 238] Parole di Tito Largi, senato- } \\
\text { re, fatte nel Senato di Roma, esortan- } \\
\text { do i nobili a stare uniti con il popolo } \\
\text { e pensare a' nuovi tumulti di guerra } \\
\text { che per le discordie di Roma s'erano } \\
\text { sollevati. }\end{array}$ \\
\hline
\end{tabular}

17) $Y$ en una fatal calamidad de estado, donde se busca [f. 129] puramente amparo y no rodeos, son elegantes y compasivas razones:

las de Adérbal, hijo de Masinisa, hecha al senado romano, que refiere Salustio en La guerra de Iugurta; ${ }^{32}$
Orationi militari di Crispo Salustio ... [p. 590] Orationi della Guerra di Iugurta. Oratione di Aderbale, figliuolo di Micissa, Re di Numidia, ilquale, essendo cacciato del regno da Iugurta, che gli haveva amazzato il fratel carnale, venuto a Roma, chiede soccorso al Senato, ed esponendo la sua miseria esorta il popolo Romano a pigliar l'armi contra Iugurta in sua difesa.

31. En Nannini aparece con las oraciones del libro segundo.

32. Nannini indica correctamente el nombre del padre de Adérbal, Micipsa, y no el de su abuelo Masinisa. 
e igual a esta fue la del embajador de Cartago al cónsul que estaba con el ejército en Útica, que refiere Apiano Alexandrino en La guerra de Cartago;

y la de Hanón, en dicho libro, suplicando que no destruyesen los romanos a Cartago;
Orationi militari d'Appiano Alessandrino, tratte da i cinque libri delle Guerre Civili ... [p. 287] Oratione d'uno ambasciadore Cartaginese a $\mathrm{i}$ consoli Romani, i quali s'erano fermati a Utica con l'esercito, per sapere la cagione della nuova guerra contra a Cartagine.

Orationi militari d'Appiano Alessandrino, tratte da i cinque libri delle Guerre Civili ... [p. 289] Parole di Annone Gella, Cartaginese, dinanzi a' consoli Romani, per impetrare che non si disfacesse Cartagine. y dos oraciones de dos embajadores de Génova al duque de Milán, que refiere Agustín Justiniano en la Historia de Génova, libro 5;
Orationi militari di monsignore Agostino Giustiniano, Genovese, raccolte da i sei libri de' suoi Annali delle cose di Genova. Del quinto libro ... [p. 883] Orationi de gli ambasciadori Genovei al Duca di Milano, invitandolo a pigliare il governo della loro città per riposarsi dalle guerre civili ... [p. 886] Seconda oratione fatta da un altro ambasciador Genovese circa la medesima materia, e questo fu Giovanni di Serra, medesimamente dottore in Legge, ilquale, seguendo al Guano e allargandosi nelle lodi del Duca, parlò a questo modo.

Orationi militari di Girolamo Faleti, tratte da gli otto libro della Guerra di Lamagna ... [p. 964] Orationi del settimo libro. Ragionamento de gli ambasciadori della città di Praga, fatto al Re di Boemia, dal quale eglino s'erano ribellati... 


\begin{tabular}{|c|c|}
\hline $\begin{array}{l}\text { y es admirable el razonamiento de la } \\
\text { reina Isabel de Hungría a su hijo, que } \\
\text { refiere Ascanio Centorio, libro } 4 \text { de su } \\
\text { Historia de Transilvania; }\end{array}$ & $\begin{array}{l}\text { Orationi militari di M. Ascanio Cen- } \\
\text { torio, tratte dai quattro libri della } \\
\text { Guerra di Transilvania ... Orationi } \\
\text { del quarto libro ... [p. 979] Parole } \\
\text { della Reina di Transilvania al Re Gio- } \\
\text { vanni, suo figliuolo, nella restitutione } \\
\text { che fece al Re de' Romani della coro- } \\
\text { na e del manto e scettro regale de i Re } \\
\text { passati di Ungheria. }\end{array}$ \\
\hline $\begin{array}{l}\text { y sumamente es eficaz la del embaja- } \\
\text { dor de Mitilene, que ofrece su ciudad } \\
\text { a la república de Lacedemonia, refe- } \\
\text { rida en Tucídides, libro } 1 \text { de su His- } \\
\text { toria }{ }^{33}\end{array}$ & $\begin{array}{l}\text { Orationi di Tucidide Ateniese, raccol- } \\
\text { te da gli otto libri delle guerre fatte tra } \\
\text { gli Ateniesi e i popoli della Morea ... } \\
\text { [p. 43] Orationi del terzo libro. Ora- } \\
\text { tione de gli ambasciadori di Mitilene } \\
\text { nel Senato de' Lacedemonii, per esor- } \\
\text { targli ad accettargli per confederati e } \\
\text { per muovergli a far nuova guerra a gli } \\
\text { Ateniesi. }\end{array}$ \\
\hline $\begin{array}{l}\text { y la que refiere Livio de los embajado- } \\
\text { res de Capua haciendo donación de } \\
\text { su ciudad al senado, es dina de pon- } \\
\text { deración y memoria. }\end{array}$ & $\begin{array}{l}\text { Orationi di Tito Livio raccolte dalle } \\
\text { sue Historie di Roma ... Orationi del } \\
\text { settimo libro della prima deca ... [p. } \\
\text { 471] Oratione de' Capovani nel Se- } \\
\text { nato di Roma chiedendo aiuto contra } \\
\text { i Sanniti. }\end{array}$ \\
\hline
\end{tabular}

18) Para recordar en ocasión conveniente un embajador al Rey que asiste los beneficios que ha recibido del suyo, abrirán puerta a nuevas razones:

[f. 129v] las del discurso de Eumenes hecha al senado después de haber ayudado a los romanos en la guerra de Antíoco, que lo escribe Livio, libro 7 , década 4.
Orationi di Tito Livio raccolte dalle sue Historie di Roma ... [p. 575] Orationi del settimo libro della quarta deca. Ragionamento d'Eumene, Re di Pergamo, nel Senato Romano, domandando alcune città in premio dell'aiuto dato loro nella guerra contra Antioco.

33. En Nannini aparece con las oraciones del libro tercero. 
19) Y para ostentar gentileza y generosidad, ofreciendo paz, tregua o liga, cuando interiores necesidades obligan a ello, y no pura virtud, es elegantísimo fundamento para añadir sobre él nuevos discursos:

la oración del libro 2 de Procopio, hecha por un embajador de los godos a Belisario;
Orationi militari di Procopio Cesariense, raccolte dai tre libro dell'historie de' gothi ... [p. 704] Orationi del secondo libro. Ragionamento d'uno ambasciadore de' Gothi a Belisario, ilquale, essendo dentro di Roma e difendendosi bravamente, haveva dato loro una grandissima rotta...

Orationi militari di Quinto Curtio, tratte da' dieci libri de' Fatti d'Alessandro Magno ... [p. 609] Orationi del quarto libro. Oratione d'uno ambasciadore di Dario mandato ad Alessandro a domandar la pace.

Orationi militari di Polibio, historico Greco, raccolte da' sei libri delle Guerre de' Romani contra le genti forestiere ... [p. 264] Del nono libro. Oratione di Clinia, ambasciatore de gli Etoli nel Consiglio de' Lacedemoni, mostrando ch'e' dovevan soccorrer più tosto loro, che unirsi con Filippo Macedone.

y elegantísima (como otra vez queda en el libro 2 de la Jerusalén liberata. 
20) Pues para agradecer un beneficio recibido y dejar juntamente empeñado al que lo hizo para adelante, no olvide el embajador:

la oración de Guido Guerra a Carlo, rey de Sicilia, que refiere Leonardo Aretino, libro 2 de su Historia de Florencia.
Orationi di Lionardo Aretino, tratte da' dodici libri dell'Historie di Fiorenza. Del secondo libro ... [p. 738] Ragionamento di Guido Guerra a Carlo, Re di Sicilia, ringratiandolo del buono animo che gli haveva verso i Guelfi e dell'apparecchio d'arme, che eglii havea fatto per rimettergli in casa.

21) Y en caso de disputa sobre la justiciación o [f. 130] agravio de alguna paz o tregua rota o quejas deste género, es dina de leerse:

la oración de los embajadores de los peruginos al senado florentín; y juntamente la respuesta del senado, que refiere Leonardo Aretino, libro 6 de su Historia de Florencia.
Orationi di Lionardo Aretino, tratte da' dodici libri dell'Historie di Fiorenza ... [p. 747] Orationi del sesto libro. Ragionamento de gli ambasciadori Perugini, fatta nel Senato di Fiorenza, lamentandosi de' Fiorentini, che senza rispetto de' confederati loro, havevan preso il possesso della città d'Arezzo.

22) Y la vez que el embajador concurriese a ocasión de haberse de elegir adónde asiste rey, cabeza, gobernador o capitán supremo, aúne a las razones que la ocasión y su ingenio le darán, las que hicieren a propósito de:

la oración que el príncipe de Flandes hizo en Jerusalén después de conquistada, que refiere Donato Aretino en su Historia de la conquista de la Tierra Santa. ${ }^{34}$
Orationi militari di Benedetto Accolti, Aretino, tratte da' quattro libri della Guerra fatta da' Christiani contra i Barbari per la ricuperatione del Sepolcro di Christo e della Giudea ... Oratione del quarto libro ... [p. 857] Oratione del Principe di Fiandra fatta a tutti i Capitani dell'esercito per deliberare di creare un Re in Gierusalem.

34. Este «Donato Aretino» es Benedetto Accolti. 
23) Y para vengar algún agravio, solicitando guerra contra otro o redimiento por este camino algún peligro o necesidad, bajo (todo) de pretesto, de piedad y razón, y no descubriendo el ánimo oculto, es notable oración:

\begin{tabular}{|l|l|}
\hline $\begin{array}{l}\text { la de Antonio sobre el cuerpo muerto } \\
\text { de César, que refiere Dion, libro 44; }\end{array}$ & $\begin{array}{l}\text { Orationi militari di Dione Casio Nice- } \\
\text { no, tratte dalle sue Historie Romane ... } \\
\text { Orationi del quarantesimoquarto libro } \\
\ldots \text { [p. 343] Oratione di Antonio fatta } \\
\text { sopra il corpo di Cesare, non tanto per } \\
\text { lodare il morto quanto per muovere il } \\
\text { popolo a pigliar l'arme contra i congiu- } \\
\text { rati e farne vendetta. }\end{array}$ \\
\hline $\begin{array}{l}\text { y la de Setimo Severo a su gente esor- } \\
\text { que se lee en Heródoto, libro 2 de su }\end{array}$ & $\begin{array}{l}\text { Orationi d'Erodoto Alicarnaseo, raccolte } \\
\text { da nove libri delle Guerre de' Greci e de' } \\
\text { Persiani ... Orationi del secondo libro } \\
\ldots \text { [p. 390] Oratione di Settimio Seve- } \\
\text { ro a' suoi soldati, radunati in un campo, } \\
\text { esponendo loro la morte di Pertinace ed } \\
\text { esortandogli a farne vendetta. }\end{array}$ \\
\hline
\end{tabular}

24) Y para malquistar un vulgo con su príncipe, república o gobierno, son singulares discursos:

el de Lucio Catilina, que refiere Salustio, libro $1[130 \mathrm{v}]$;

[p. 586] Orationi militari di Crispo Salustio. Oratione di Lucio Catilina a i congiurati, $i$ quali s'erano congregati in casa sua, nella quale ei gli esorta a star saldi nel proposito della liberatione della patria.

y el de Casio a su ejército esortándolo a la libertad de la patria, libro 4 de Apiano Alexandrino:

Orationi militari d'Appiano Alessandrino, tratte da i cinque libri delle Guerre Civili ... [p. 308] Orationi del quarto libro. Oratione di Cassio al suo esercito prima ch'ei seguisse la giornata de' campi Filippici, esortandogli a mostrarsi valorosi per la libertà della patria, come egli e gli altri congiurati s'eran mostrati arditi nell'ammazzare il tiranno.

35. «Heródoto» es, obviamente, un error. Nannini hace la atribución correcta a Herodiano. 
y la del Conestagio, libro 2, puesta en $\mathrm{X}$ cabeza del duque de Alba, citada ya otra vez.

25) $Y$ al contrario, para sosegar el tumulto de un pueblo y reducirlo a la primera quietud para que le abra camino al logro de sus disinios, consulte el embajador que lo tratare:

la oración de Cicerón hecha al pueblo después de la muerte de César que se lee en Dion, libro 44 de su Historia romana; y esto baste por ahora.
Orationi militari di Dione Casio Niceno, tratte dalle sue Historie Romane ... Orationi del quarantesimoquarto libro ... [p. 337] Oratione di Cicerone al popolo e Senato Romano, il quale s'era levato in arme per la morte di Cesare, fatta per fermare gli animi de' popoli, dubitando che non si facesse tumulto, come suole accadere nelle rivolutioni de gli stati. 


\section{Bibliografía}

Amezúa, Agustín G. de, Lope de Vega en sus cartas. Introducción al epistolario de Lope de Vega Carpio, vol. IV, Madrid, Tipografía de Archivos, 1943.

BouzA, Fernando, «Historia natural del texto escrito. Autores, copistas, impresores, libreros y lectores», en Comunicación, conocimiento y memoria en la España de los siglos XVI y XVII, Salamanca, SEMYR, 1999, pp. 79-105.

Cantarino, Elena, "Justo Lipsio en la biblioteca de Lastanosa. Apuntes para las fuentes de Gracián», en María Luisa Lobato y Francisco Domínguez Matito, eds., Actas del VI Congreso de la Asociación Interanacional Siglo de Oro, Madrid, Iberoamericana-Vervuert, 2004, vol. 1, pp. 457-465.

Cevolini, Alberto, De arte excerpendi. Imparare a dimenticare nella modernità, Florencia, Olschki, 2006.

Cinti, Bruna, Letteratura e politica in Juan Antonio de Vera, ambasciatore spagnolo a Venezia (1632-1642), Venecia, Librería Universitaria Editrice, 1966.

Colomer, José Luis, "Introducción. Los senderos cruzados del arte y la diplomacia», en José Luis Colomer, ed., Arte y diplomacia de la monarquía hispánica en el siglo XVII, Madrid, Fernando Villaverde Ediciones, 2003, pp. 13-32.

Davies, Gareth A. , «The Influence of Justus Lipsius on Juan de Vera y Figueroa’s Embaxador (1620)», Bulletin of Hispanic Studies 42.3 (1965), pp. 160-173.

Delage, Agnès, «L'historien comme fiction. Stratégies d'auteurs et stratégies narratives dans l'historiographie espagnole du XVIIe siècle», en Clizia Carminati y Valentina Nider, eds., Narrazione e storia tra Italia e Spagna nel Seicento, Trento, Università degli Studi di Trento, 2007, pp. 141-163.

EgIDO, Aurora, «Introducción», en Baltasar Gracián, El discreto, Madrid, Alianza Editorial, 1997, pp. 7-128.

Elliott, John H., El Conde-Duque de Olivares. El político en una época de decadencia, trad. Teófilo de Lozoya, Barcelona, Crítica, 1990.

Fernández-Daza Áluarez, Carmen, Juan Antonio de Vera, I Conde de la Roca (1583-1658), Badajoz, Diputación Provincial, 1994 a.

—, «Lope de Vega y Juan Antonio de Vera», Anuario de Estudios Filológicos 17 (1994b), pp. 115-131.

Iglesias-Zoido, Juan Carlos y Victoria Pineda, eds., Anthologies of historiographical discourses from Antiquity to the Renaissance, Leiden, Brill, (en prensa). Mattingly, Garrett, Renaissance Diplomacy, Baltimore, Penguin Books, 1965.

López López, Raúl, ed., Pedro de Valencia, «Sobre las Guerras de Flandes de Jerónimo Conestaggio", en Pedro de Valencia, Obras completas VI. Escritos varios, coord. Jesús María Nieto Ibáñez, León, Universidad de León, 2012, pp. 575-613.

Montero, Juan, «Olivares y los ingenios andaluces. Sobre el mecenazgo literario del conde-duque», Andalucía en la historia 36 (2012), pp. 16-19. 
Moss, Ann, Printed Commonplace Books and the Structuring of Renaissance Thought, Oxford, Clarendon Press, 1996.

NAKLÁDALOvá, Iveta, «Las artes excerpendi altomodernas y la organización del saber», en Natalia Fernández Rodríguez y María Fernández Ferreiro, eds., Literatura medieval y renacentista en España: lineas y pautas, Salamanca, Sociedad de Estudios Medievales y Renacentistas, 2012, pp. 763-773.

Ramírez de Villa-Urrutia, Wenceslao, «La literatura del derecho internacional en España durante el siglo XVII», en Ocios diplomáticos, 2a ed., Madrid, Francisco Beltrán, 1927, pp. 171-192.

Rodríguez Moñino, Antonio, «El Conde de la Roca (1583-1658). Noticias bio-bibliográficas», Revista del Centro de Estudios Extremeños 9 (1935), pp. 18-31.

Salazar de Mendoza, Pedro, Monarquía de España, ed. Bartolomé Ulloa, tomo 2, Madrid, Ibarra, 1770.

Vega Carpio, Lope de, La Circe, con otras rimas y prosas, Madrid, Viuda de Alonso Martín a costa de Alonso Pérez, 1624.

-, Los esclavos libres, ed. Omar Sanz Burgos y Ely Treviño, en Lope de Vega. Comedias. Parte XIII, coord. Natalia Fernández, Madrid, Gredos, 2014, t. I, pp. 536-565.

Vera y Figueroa, Juan Antonio, El embajador, Sevilla, Francisco de Lyra, 1620.

-, Juan Antonio, El enbaxador, ed. facsímil, ed. introd. [José Manuel López Balboa], Madrid, [Artes Gráficas Arges], 1947.

VIVes, Juan Luis, De tradendis disciplinis, Colonia, apud Ioannem Gymnicum, 1536.

Yeo, Richard, Notebooks, English Virtuosi and Early Modern Science, Chicago, The University of Chicago Press, 2014. 
